\title{
Inter-calibration of SAR data series for offshore wind resource assessment
}

\author{
Badger, Merete; Ahsbahs, Tobias Torben; Maule, Petr; Karagali, loanna
}

Published in:

Remote Sensing of Environment

Link to article, DOI:

10.1016/j.rse.2019.111316

Publication date:

2019

Document Version

Peer reviewed version

Link back to DTU Orbit

Citation (APA):

Badger, M., Ahsbahs, T. T., Maule, P., \& Karagali, I. (2019). Inter-calibration of SAR data series for offshore wind resource assessment. Remote Sensing of Environment, 232, [111316].

https://doi.org/10.1016/j.rse.2019.111316

\section{General rights}

Copyright and moral rights for the publications made accessible in the public portal are retained by the authors and/or other copyright owners and it is a condition of accessing publications that users recognise and abide by the legal requirements associated with these rights.

- Users may download and print one copy of any publication from the public portal for the purpose of private study or research.

- You may not further distribute the material or use it for any profit-making activity or commercial gain

- You may freely distribute the URL identifying the publication in the public portal 
Inter-calibration of SAR data series for offshore wind resource assessment

Merete Badger $^{\mathrm{a}^{*}}$, Tobias Ahsbahs ${ }^{\mathrm{a}}$, Petr Maule ${ }^{\mathrm{a}}$, Ioanna Karagali ${ }^{\mathrm{a}}$

${ }^{a}$ Technical University of Denmark, Department of Wind Energy, Frederiksborgvej 399, 4000 Roskilde, Denmark, e-mail mebc@dtu.dk

*Corresponding author

Highlights

- Offshore wind resource assessment requires long-term wind data records.

- Wind speed retrievals from different European SAR sensors are offset.

- Biases vary over time and according to scan modes and incidence angles.

- Inter-calibration can remove biases and improve the accuracy on wind resources.

Abstract

Wind observations in the marine environment are both costly and sparse. This makes wind retrievals from satellite Synthetic Aperture Radar (SAR) an attractive option in connection with planning of offshore wind farms. Because the wind power density is proportional to the wind speed cubed, it is important to achieve the highest possible absolute accuracy on SAR wind speed retrievals for wind energy applications. A method is presented for intercalibration of SAR observations from Envisat and Sentinel-1A/B. Sensor-specific effects on the SAR-retrieved wind speeds are first quantified through comparisons against collocated ocean buoy observations. Based on global circulation model simulations of wind speed and direction, we retrieve the Normalized Radar Cross Section (NRCS) for different radar incidence angles. Residuals between the retrieved and the observed NRCS are used to intercalibrate the observed NRCS before reprocessing to SAR wind fields. The inter-calibration 
27 leads to an improved agreement between SAR and buoy wind speeds with biases below $0.2 \mathrm{~m}$

$28 \mathrm{~s}^{-1}$ for all investigated SAR sensors. Estimates of the wind resource improve with respect to

29 the buoy observations for ten of the twelve sites investigated. The average deviation between

30 wind power densities is reduced from $20 \%$ to $8 \%$ as the SAR inter-calibration leads to more

31 conservative estimates of the wind resource.

32

33 Keywords

34 Inter-calibration, offshore wind energy, resource, Synthetic Aperture Radar, Sentinel-1,

35 Envisat

36 
1. Introduction

The Sentinel-1 mission by the European Space Agency (ESA) has secured the availability of Synthetic Apertur Radar (SAR) observations for ocean wind mapping for the years to come. Sentinel-1A (2014-present) and Sentinel-1B (2016-present) are designed for continuation of the previous ESA mission Envisat, which delivered SAR data during 2002-12. SAR instruments are active sensors, which transmit and receive pulses in the microwave range. Properties of the ocean surface waves determine the measured return signal. A C-band SAR sensor is sensitive to waves of the cm-scale, which are typically generated by the instantaneous wind stress at the sea surface.

Based on scatterometer observations, empirical relationships have been established between radar backscatter from the sea surface and wind speed at the height $10 \mathrm{~m}$. A similar principle can be applied to retrieve wind speeds from SAR observations at a higher spatial resolution and with full coverage over coastal seas (Karagali et al., 2013). Geophysical Model Functions (GMF) for wind speed retrieval at C-band include CMOD4 (Stoffelen and Anderson, 1997), CMOD-IFR2 (Quilfen et al., 1998), CMOD5 (Hersbach et al., 2007), CMOD5.n (Hersbach, 2010), CMOD6 and CMOD7 (Stoffelen et al., 2017). The CMOD functions are developed for radar observations with vertical polarization in transmit and receive (VV) and a polarization ratio must be applied in order to compensate for the lower signal at HH (Liu et al., 2013; Mouche et al., 2005; Thompson et al., 1998). A new model function called C_SARMOD2 is developed directly from RADARSAT-2 and Sentinel-1 SAR observations (Lu et al., 2018).

Wind speed retrievals from Envisat have been compared to in situ observations in different parts of the world (Chang et al., 2015; Doubrawa et al., 2015; Hasager et al., 2015a; 2015b; 2011; Takeyama et al., 2013a; 2013b) and evaluations of wind speeds from Sentinel-1 are 
also published (Ahsbahs et al., 2018; Lu et al., 2018; Monaldo et al., 2016). The Root Mean Square Error (RMSE) of the SAR wind speed with respect to reference data sets is typically less than $2.0 \mathrm{~m} \mathrm{~s}^{-1}$ whereas the bias can vary largely. The temporal and spatial scales of wind data should be considered in any comparison analysis (Hasager et al., 2002). Likewise, care must be taken to compare consistently either the real winds or the Equivalent Neutral Wind (ENW) (Kara et al., 2008; Portabella and Stoffelen, 2009).

The installed wind power capacity is growing rapidly around the world and plans for new installations offshore are ambitious; particularly in Europe and Asia. In order to produce robust estimates of the wind resource, the highest possible number of independent wind speed observations is needed. The sampling frequency, which can be achieved from polar-orbiting satellites, is poor compared to the sampling frequencies of typical in situ sensors or numerical models. The strength of satellite wind fields lie in the observation of large spatial domains over extensive periods. In order to maximize the number of available satellite wind fields for wind resource assessment, the opportunity to combine data series from different sensors is very attractive. However, effects of sensor-specific characteristics need to be taken into account before the data series can be merged.

Satellite data merging is performed in connection with Climate Data Records (CDRs) defined as "time series of measurements of sufficient length, consistency and continuity to determine climate variability and change” (National Research Council, 2004). Merged time-series from various sensors and for different physical parameters such as ocean surface winds from scatterometers (Elyouncha and Neyt, 2013; Wentz et al., 2017), ice sheet elevation from altimeters (Khvorostovsky, 2012), and temperature from microwave sounders (Christy et al., 1998) already exist. Although the record of wind retrievals from space is not yet long enough 
to determine climate variability and change, the community effort is to generate consistent and stable time-series. Inter-calibration ensures consistency between products from different sensors and it can be performed using reference data sets of in situ observations and intercomparison among different products (Zeng et al., 2015).

The objective of this paper is to inter-calibrate SAR observations from Envisat and Sentinel-1 SAR and combine them to a single data series suitable for wind speed retrieval and resource assessment. Section 2 describes the data sets analyzed and the pre-processing applied. In Section 3, we present a series of initial comparisons between SAR-retrieved wind speeds and ocean buoy observations. A method for inter-calibration of the SAR observations is given in Section 4. In Section 5, comparisons against the reference data set are shown after SAR intercalibration. The effect of SAR inter-calibration on wind resource estimation is examined in Section 6. Our findings are discussed in Section 7 and conclusions are given in Section 8.

\section{Data and pre-processing}

\subsection{Satellite SAR wind maps}

This analysis is based on Level-1 SAR data from Envisat and Sentinel-1 A/B, which are available from the Copernicus Open Access Hub at https://scihub.copernicus.eu/. Our focus is on scenes acquired in ScanSAR mode i.e. the Envisat Wide Swath Mode (WSM) and the Sentinel-1 Interferometric Wide Swath (IW) and Extra Wide Swath (EW) Modes. The swath width is fixed at $400 \mathrm{~km}$ for WSM and EW and $250 \mathrm{~km}$ for IW whereas the length of scenes is variable. All available products covering the seas of Northern Europe (Figure 1) have been downloaded for the period 2002/08/20 to 2018/05/31. Sentinel-1A products generated after 2015/11/25 at 10:40 UTC are processed with a radiometric performance enhancement 
whereas only some of the scenes acquired during the commissioning phase of Sentinel-1A have been reprocessed (Miranda, 2015). Calibration inconsistencies are therefore still present for the early Sentinel-1A data. The radiometric accuracy of Sentinel-1B observations has been satisfactory, and also compatible with that of Sentinel-1A, since launch (Schwerdt et al., 2017).

Retrieval of wind speed maps from the Envisat and Sentinel-1 SAR scenes is performed with the SAR Ocean Products System (SAROPS) developed by the Johns Hopkins University, Applied Physics Laboratory and the US National Atmospheric and Oceanographic Administration (NOAA) (Monaldo et al., 2014). The CMOD5.n (Hersbach, 2010) function is chosen for the wind speed inversion and the polarization ratio of Mouche et al. (2005) with incidence angle dependence is applied to the scenes acquired in HH. Regardless of the original resolution of satellite SAR products, we average pixels to a size of $0.5 \mathrm{~km}$ prior to the wind retrieval processing to reduce effects of random noise and of surface inclination due to longer-period ocean waves. This is common practice for SAR wind retrievals (Dagestad et al., 2012).

Because several wind speed and direction pairs may correspond to a single value of backscatter intensity from SAR, information about the wind direction is needed in order to retrieve the wind speed. We obtain the wind directions from the Climate Forecast System Reanalysis (CFSR, http://nomads.ncdc.noaa.gov/data.php?name=access\#cfs-reanal-data) during 2002-10 and from the Global Forecast System (GFS) at $0.50^{\circ}$ resolution during 201012 (http://nomads.ncdc.noaa.gov/data/gfsanl) and at $0.25^{\circ}$ resolution from 2014 onwards (tp://ftp.ncep.noaa.gov/pub/data/nccf/com/gfs/prod). The model outputs are interpolated spatially to match the grid cells of the SAR scenes. 
Land surfaces are masked out during the SAR wind processing using the Global Self-

consistent, Hierarchical, High-resolution Geography Database

(http://www.soest.hawaii.edu/pwessel/gshhg/). Sea ice is detected using the IMS Daily

141 Northern Hemisphere Snow and Ice Analysis

142 (http://nsidc.org/data/docs/noaa/g02156_ims_snow_ice_analysis/). The collection of SAR

143 wind maps used as the starting point for our analyses is available at

144 https://satwinds.windenergy.dtu.dk/.

\subsection{Ocean buoy observations}

147 Observations from ocean buoys are gathered for the North Sea and part of the North Atlantic

148 for the years 2002 to 2018. To prevent biases, the following criteria are set for buoy stations

149 to be included in this analysis: i) a station must deliver data during the period 2006 to 2017 or

150 longer; ii) no significant change of the buoy position has occurred over time; and iii) the buoy

151 is located at least $10 \mathrm{~km}$ from the shoreline. A total of 12 buoy stations live up to the criteria

152 and these datasets are from three institutions: UK MetOffice (personal communication), the

153 Irish Meteorological Service, Met Éireann

154 (https://erddap.marine.ie/erddap/tabledap/IWBNetwork.html), and the Bundesamt für

155 Seeschifffahrt und Hydrography, BSH (http://nwsportal.bsh.de/).

157 The MetOffice and Met Éireann used Ocean Data Acquisition Systems (ODAS) buoys in the 158 early years and some of them have later been replaced with buoys from the manufacturer 159 Fugro. Data from BSH is obtained from light vessels and one moored buoy. Figure 1 shows 160 the buoy locations. Position data from the MetOffice buoys are truncated to $0.1^{\circ}$ 161 corresponding to an uncertainty of roughly $10 \mathrm{~km}$ on the position. The buoy data are quality 

performed in connection with this analysis.

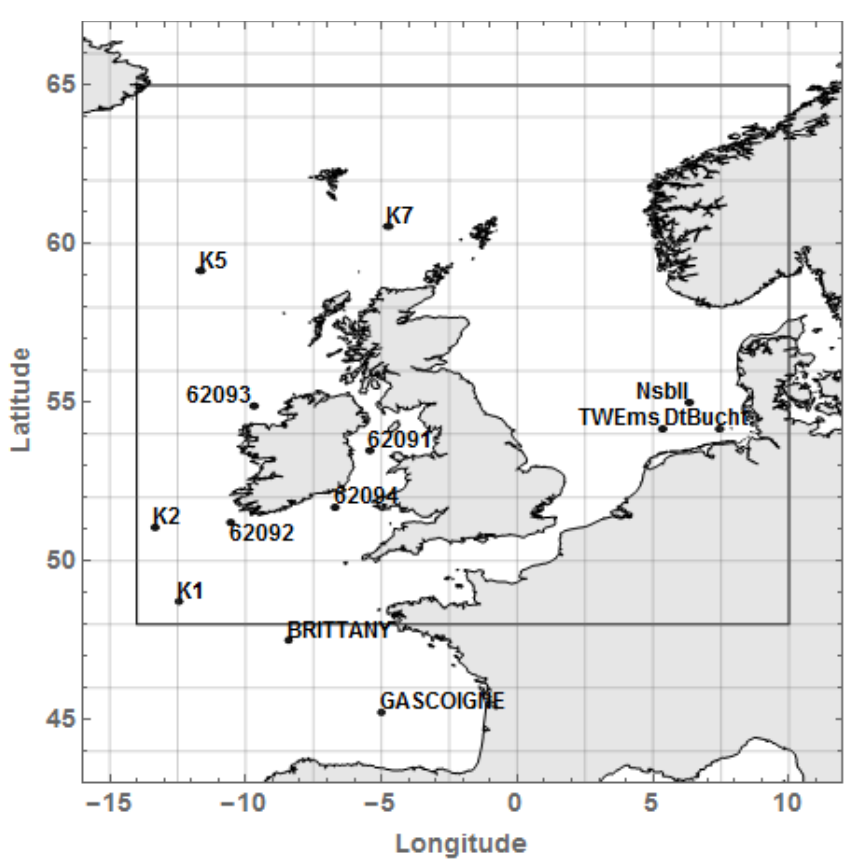
$0.0002 \mathrm{~m}$

Figure 1. The area investigated and positions of the buoys used in this study. The inner domain shows the area used for SAR inter-calibration in Section 4.

The buoy wind speeds and directions are recorded hourly. Measurement heights vary between $3.5 \mathrm{~m}$ and $14 \mathrm{~m}$ with the vast majority of the observations at heights lower than $10 \mathrm{~m}$. We extrapolate to 10-m wind speeds using a logarithmic wind profile:

where $u(z)$ is the wind speed at height $z\left(\mathrm{~m} \mathrm{~s}^{-1}\right), u *$ is the friction velocity $\left(\mathrm{m} \mathrm{s}^{-1}\right), \kappa$ is the von Kármán constant ( $\sim .4)$, and $z_{0}$ is the surface roughness length, which we set to a constant of 
The air-sea temperature difference, which is needed to estimate atmospheric stability effects, is typically missing in the buoy data sets. We can thus expect a bias on the $10-\mathrm{m}$ wind speed due to the lack of stability correction of the buoy observations. We assume this bias is constant across the Envisat and Sentinel-1 sensing periods.

\section{Initial comparisons of SAR and buoy observations}

We first compare the wind speeds retrieved from SAR to wind speed observations from the ocean buoys in the North Sea and North Atlantic. The selection criterion for buoy observations is that their time stamp must be less than 30 minutes from each SAR data acquisition time. To ensure comparability between spatial averaging of the satellite winds and temporal averaging of the buoy observations, we extract the average SAR wind speeds over an area of $10 \mathrm{~km}$ by $10 \mathrm{~km}$ around the buoy positions. We exclude data points where the SAR or buoy wind speeds are below $0.5 \mathrm{~m} \mathrm{~s}^{-1}$.

Buoys provide real wind speeds whereas the SAR wind retrievals are expressed as ENW, which are cleaned for atmospheric stability effects and $0.2 \mathrm{~m} \mathrm{~s}^{-1}$ higher on average (Kara et al., 2008; Portabella and Stoffelen, 2009). Here, we are primarily interested in the consistency between wind retrievals from Envisat and Sentinel-1. Assuming again that the long-term average stability conditions are similar across sensing periods, we can compare the SAR and buoy wind speeds for this purpose without further correction.

Figure 2 shows scatterplots of the buoy wind speeds versus the wind speeds retrieved from SAR. A total of 3099 collocated pairs of Envisat and buoy wind speeds are available and the comparison shows a RMSE of $2.37 \mathrm{~m} \mathrm{~s}^{-1}$. The mean wind speed from Envisat is $0.87 \mathrm{~m} \mathrm{~s}^{-1}$ 
higher than from the buoy observations. For wind speeds beyond $20 \mathrm{~m} \mathrm{~s}^{-1}$, the SAR wind 203 speeds are lower than the buoy wind speeds.

204

205 For the subset of Sentinel-1A scenes acquired during the commissioning phase, the

206 comparison show a RMSE of $2.01 \mathrm{~m} \mathrm{~s}^{-1}$ and a positive bias for all wind speed bins up to $16 \mathrm{~m}$

$207 \mathrm{~s}^{-1}$. The SAR wind speeds are on average $0.97 \mathrm{~m} \mathrm{~s}^{-1}$ higher than the buoy wind speeds. For the 208 later Sentinel-1A scenes, the RMSE is $1.57 \mathrm{~m} \mathrm{~s}^{-1}$. Comparisons for Sentinel-1B show almost

209 similar results with RMSE of $1.58 \mathrm{~m} \mathrm{~s}^{-1}$. For both Sentinel-1 sensors, SAR wind speeds

210 overestimate the buoy wind speeds in the low-wind range. When the wind speed is within the

211 range 7-17 $\mathrm{m} \mathrm{s}^{-1}$, SAR and buoy wind speeds are almost equal and beyond that, the buoy wind

212 speeds are higher. The average bias for Sentinel-1A and B after commissioning is only 0.10-

$213 \quad 0.17 \mathrm{~m} \mathrm{~s}^{-1}$ and wind speeds from these two sets of SAR observations are very consistent with

214 each other. There is an offset with respect to wind retrievals from Envisat and Sentinel-1A

215 observations during commissioning. 

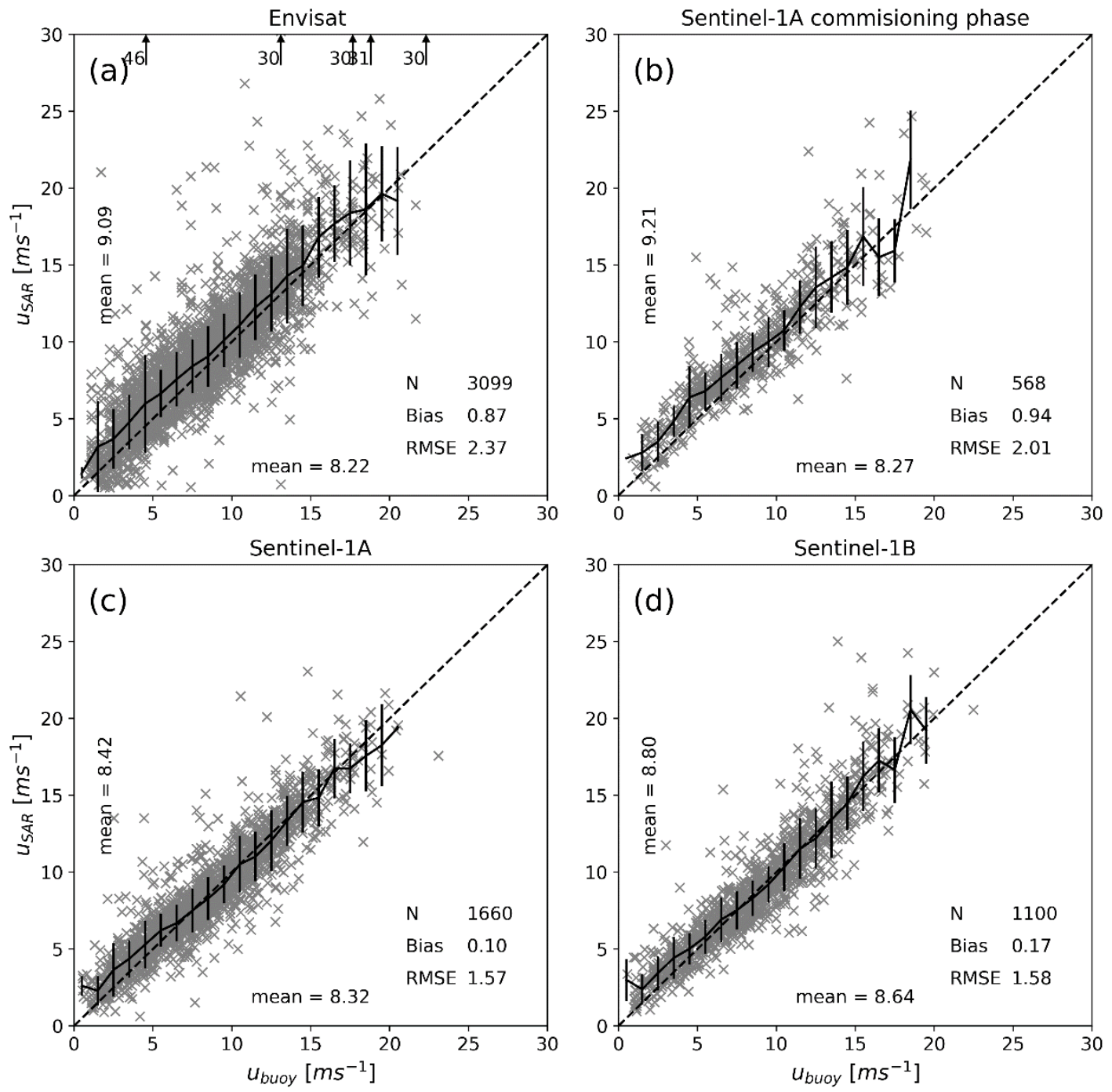

217 Figure 2. Comparisons of wind speeds retrieved from SAR against buoy wind speeds for (a)

2203.1 Wind speed dependence on the wind direction input

221 To examine the effect of the wind direction input chosen for the SAR wind retrieval

222 processing, we repeat the comparisons between SAR and buoy wind speeds using a second

223 set of SAR wind speeds retrieved over each of the buoy stations with observed wind 
directions from the buoys as input. The buoy wind directions are expected to be more accurate than the model wind directions initially used for the SAR wind retrieval because $i$ ) they are representative for the exact buoy locations, $i$ ) they are measured in a consistent manner across the Envisat and Sentinel-1 sensing periods, and iii) they are observed rather than simulated.

Table 1. Summary of comparisons between SAR and buoy wind speeds. The SAR wind speeds are retrieved with wind directions from a model and from buoy observations.

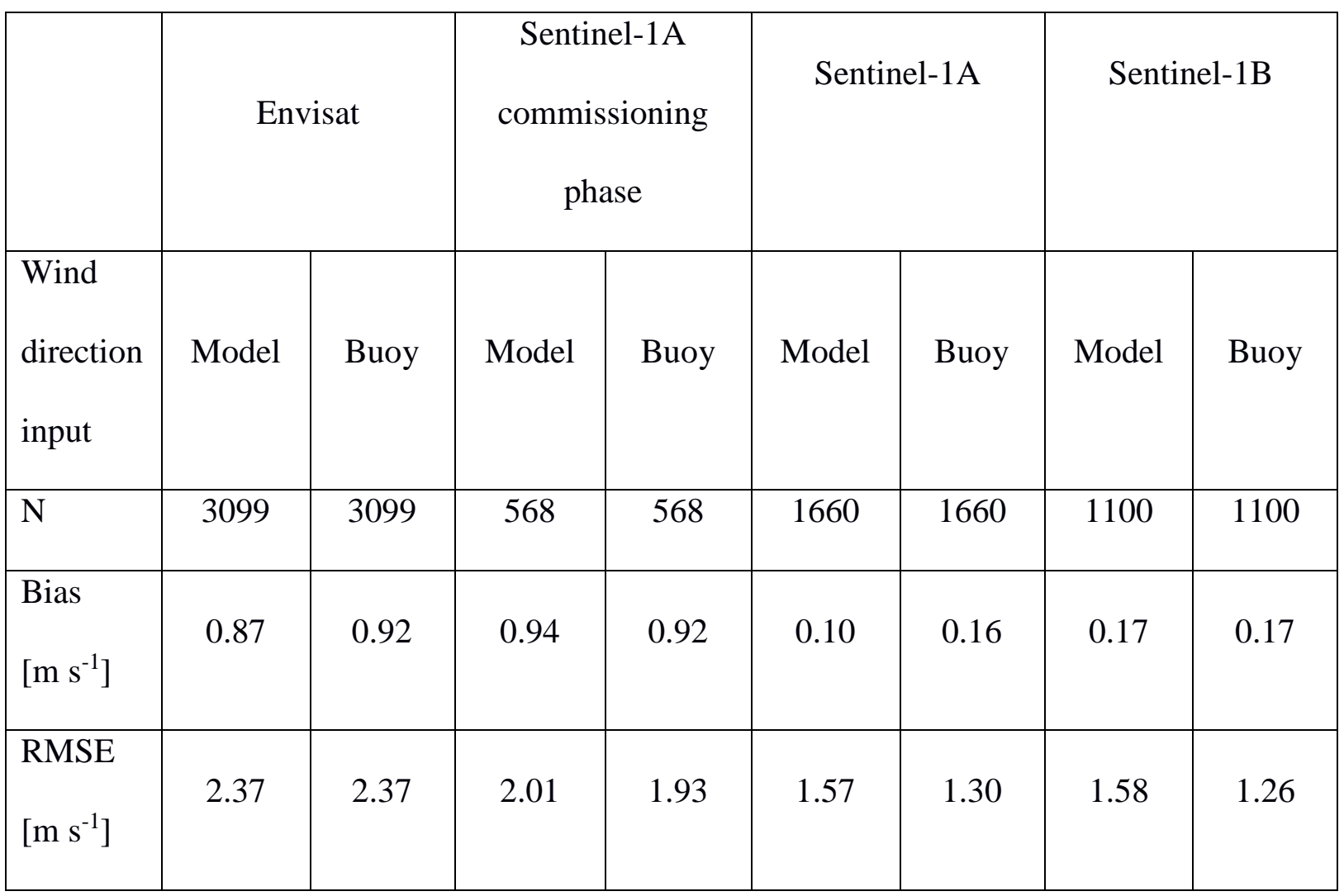

Table 1 shows the comparisons of SAR and buoy wind speeds when modelled vs. buoy wind directions are used to drive the wind speed retrieval from SAR. For Envisat, the RMSE is unchanged $\left(2.37 \mathrm{~m} \mathrm{~s}^{-1}\right)$ and the positive bias has increased by $0.05 \mathrm{~m} \mathrm{~s}^{-1}$ with respect to the comparison in Figure 2. For all Sentinel-1 data subsets, a small improvement of the RMSE is seen whereas the bias changes by less than $0.1 \mathrm{~m} \mathrm{~s}^{-1}$. The offset between winds from Envisat 
and Sentinel-1 after commissioning remains around $0.8 \mathrm{~m} \mathrm{~s}^{-1}$ so the quality of wind direction inputs cannot explain the offsets in wind speed biases between different SAR sensors. Because we find the lowest RMSE for SAR wind speeds retrieved with buoy wind directions, we use these SAR wind retrievals for the remaining part of Section 3.

The comparisons presented above all indicate that SAR winds retrieved systematically with CMOD5.n overestimate the observed wind speed at low to moderate wind speeds. The positive bias is larger for Envisat and Sentinel-1 during commissioning than for the later Sentinel-1 data series. At high wind speeds, SAR winds retrieved from Envisat and Sentinel-1 during commissioning still overestimate the observed wind speeds whereas wind speeds retrieved from the later Sentinel-1 data series match the reference wind speeds well. The wind speed biases, which we find for the different SAR sensors and periods, cannot be explained by inconsistencies in the ancillary data used to drive the SAR wind retrieval. We therefore turn to examine the effect of different SAR sensing properties on the wind speed accuracy.

3.2 Wind speed dependence on the radar polarization

To investigate the effect of radar polarization on the wind retrieval accuracy, we separate SAR scenes acquired in $\mathrm{HH}$ and VV. We can expect the best accuracy at VV polarization since CMOD5.n can be applied directly without a polarization ratio. The majority of SAR scenes in our data set have VV polarization.

Table 2 shows results of comparisons between SAR and buoy wind speeds at VV and $\mathrm{HH}$ polarization for Envisat and Sentinel-1. The RMSE is significantly lower for VV than $\mathrm{HH}$ for all data sets except Sentinel-1B. This is as expected due to the added uncertainty introduced by the polarization ratio we apply to SAR observations acquired with HH-polarization (cf. 
Section 1). A positive bias remains for the VV scenes and there is now an average offset of 0.69-0.73 $\mathrm{m} \mathrm{s}^{-1}$ between Envisat and Sentinel-1 retrievals. Envisat scenes acquired in $\mathrm{HH}$ show a large RMSE and a positive bias for all wind speed bins. Sentinel-1 scenes acquired in $\mathrm{HH}$ are associated with a large uncertainty due to the low number of collocated wind speed samples from SAR and the buoys.

Table 2. Summary of comparisons between SAR and buoy wind speeds divided according to sensor and polarization.

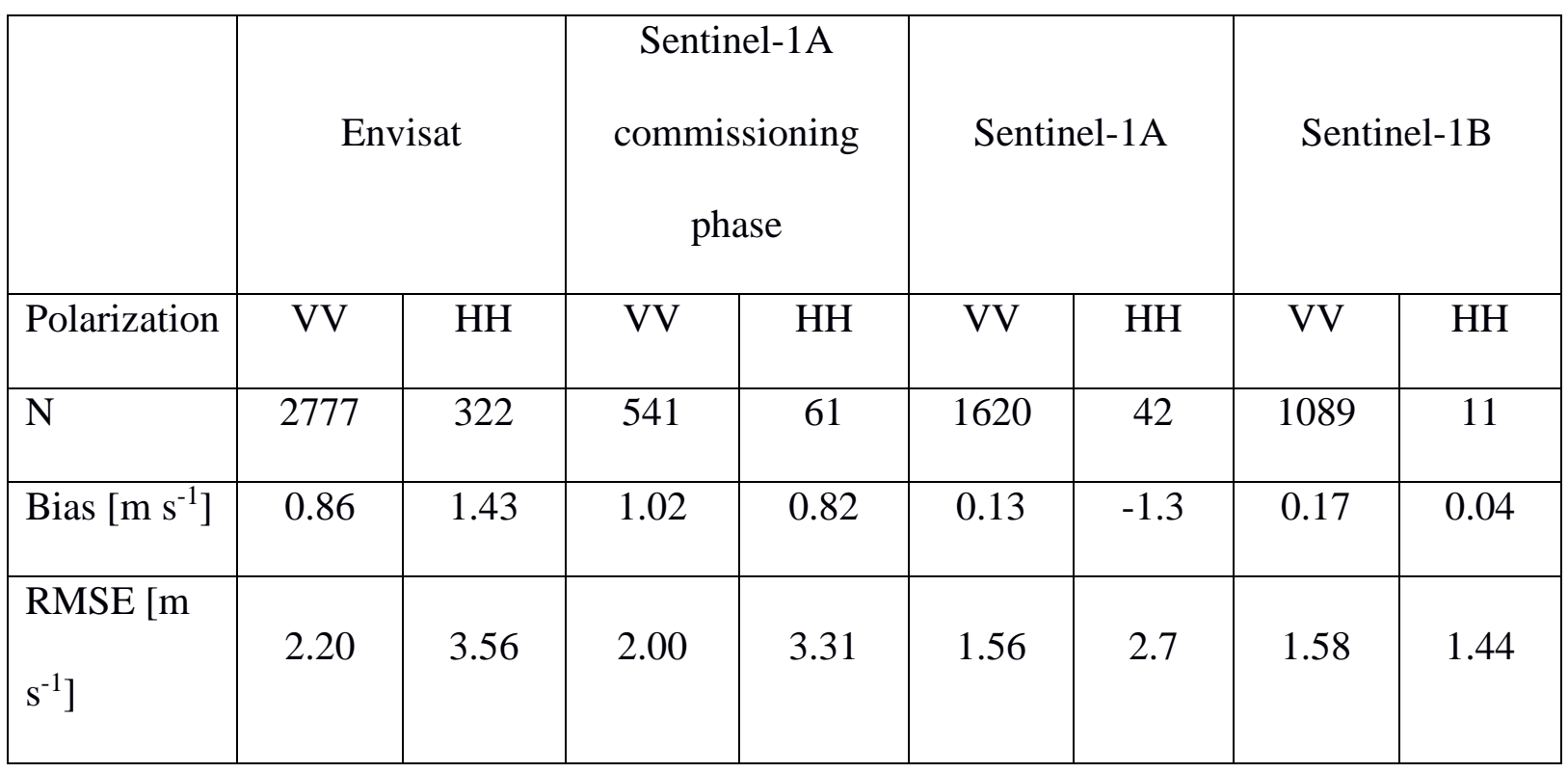

3.3 Wind speed dependence on the radar incidence angle

Based on the collocated SAR and buoy wind speed pairs analyzed above, we investigate the dependence on the SAR-buoy wind speed residuals on the radar incidence angle. Visual inspection of the SAR derived wind fields indicate that wind speeds can vary across the radar swath even though the radar incidence angle is taken into account during the SAR wind retrieval. Higher wind speeds typically occur at high incidence angles. 
Figure 3 shows the SAR-buoy wind speed residuals as a function of the radar incidence angle. For Envisat, the average wind speed residuals are lower than $1 \mathrm{~m} \mathrm{~s}^{-1}$ for incidence angles within the range $20-35^{\circ}$. Below and above this interval, we see a change of the wind speed residuals as a function of incidence angle. The residuals are always positive indicating higher SAR wind speeds compared to the buoy wind speeds. The standard deviation, represented by the error bars, is very high for incidence angles lower than $20^{\circ}$. At all other incidence angles, the standard deviation is $+/-2 \mathrm{~m} \mathrm{~s}^{-1}$ or less.

Most Sentinel-1 samples are obtained within the incidence angle range of $30-45^{\circ}$ but a few data points lie within the range of $20-30^{\circ}$. During the commissioning phase of Sentinel-1A, we see large fluctuations of the wind speed residuals and error bars of up to $+/-3 \mathrm{~m} \mathrm{~s}^{-1}$. Average wind speed residuals for the later Sentinel-1A acquisitions and for Sentinel-1B are always within the range $+/-1 \mathrm{~m} \mathrm{~s}^{-1}$ and the standard deviation remains within $+/-2 \mathrm{~m} \mathrm{~s}^{-1}$. A trend of slightly increasing wind speed residuals with increasing incidence angles is seen in Figure 3 c) and d).

Our analyses so far have indicated a consistent difference between wind speed retrievals from Envisat vs. Sentinel-1 A/B, which persists regardless of the wind direction input and the SAR polarization and increases with the SAR incidence angle. To investigate the incidence angle dependence further, we extend the analyses to the Normalized Radar Cross Section (NRCS) input to the SAR wind retrievals. 

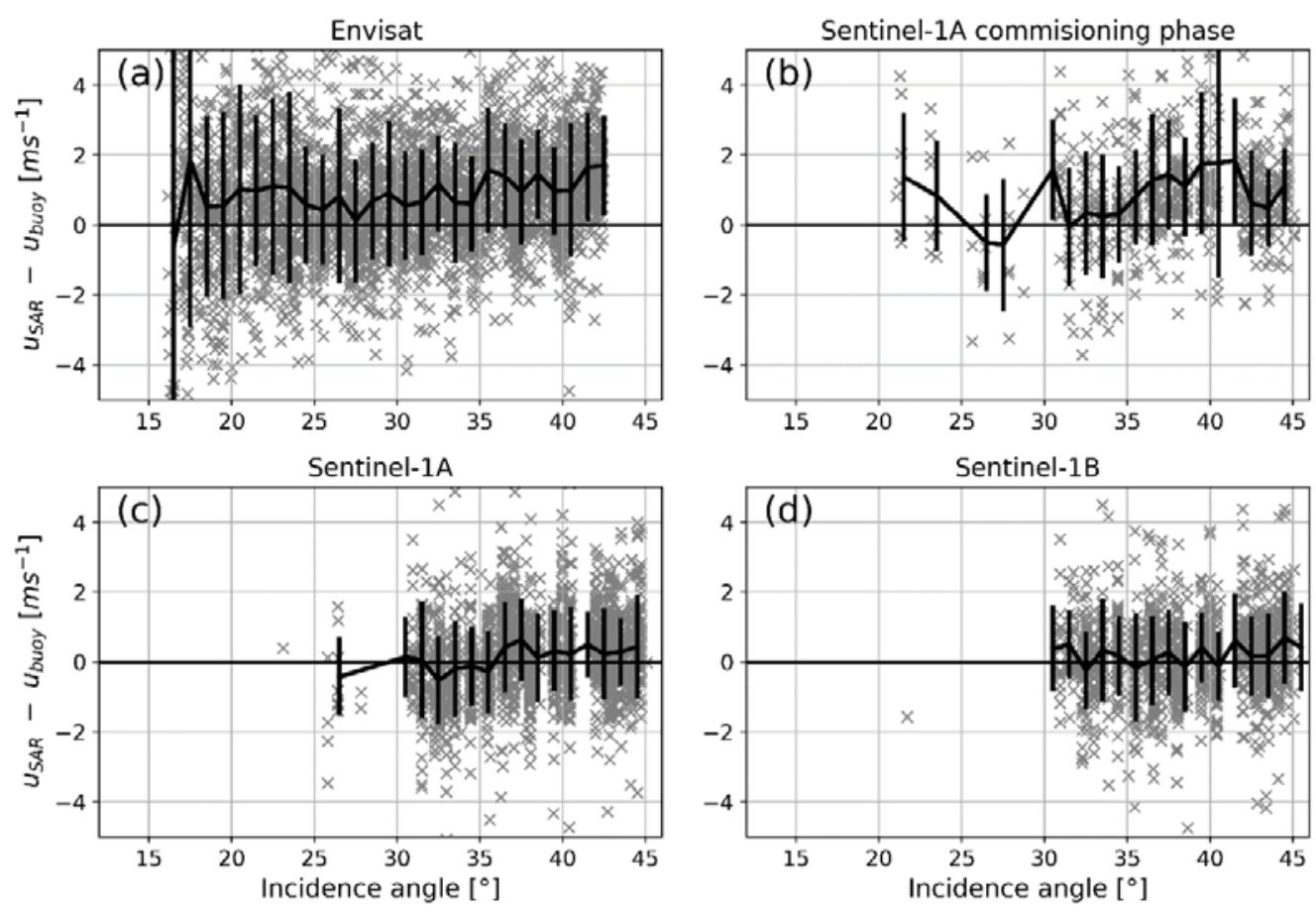

Figure 3. Residuals between SAR and buoy wind speeds as a function of radar incidence

angle for (a) Envisat; (b) Sentinel-1A commissioning phase; (c) Sentinel-1A; and (d) Sentinel-

3.4 NRCS dependence on the radar incidence angle

In the following, we use buoy wind speeds and directions to retrieve the NRCS for different radar incidence angles. To achieve this, we apply CMOD5.n in forward mode i.e. we use the buoy wind speed and direction and the radar incidence angle as input and retrieve the NRCS.

We then compare the observed and retrieved NRCS.

Comparisons of observed and retrieved NRCS from buoy winds are shown in Figure 4. For

Envisat, the residual of NRCS [dB] is very small at low incidence angles and it increases gradually for incidence angles larger than $20^{\circ}$. The relationship between the incidence angle and the NRCS residuals in $\mathrm{dB}$ space is almost linear. For the Sentinel-1A commissioning phase, a linear relationship between NRCS residuals and the incidence angle is seen across 
the interval $32-41^{\circ}$ and there are very few data points at lower incidence angles. For Sentinel-

$3161 \mathrm{~A} / \mathrm{B}$, the incidence angle range is smaller and the observed NRCS is higher than for Envisat.

317 This leads to smaller residuals with respect to the retrieved NRCS and again, we see a linear

318 increase of NRCS with the incidence angle. The results in Figure 4 suggest that changes of

319 NRCS residuals with the radar incidence angle is the source of the wind speed biases reported

320 above. In the following, we present a method for correction of the sensor-specific incidence

321 angle dependence.
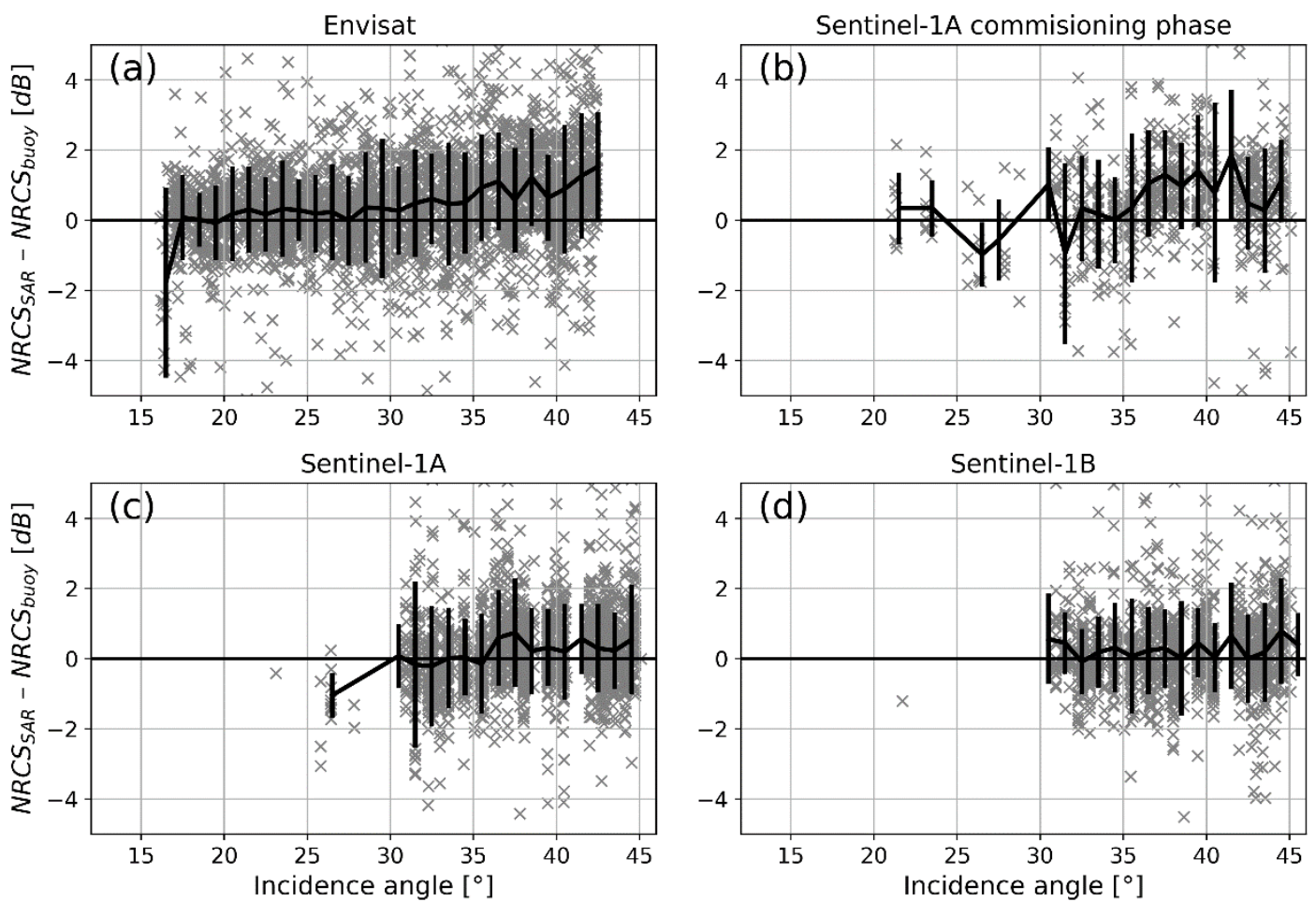

Figure 4. Residuals between measured and retrieved NRCS using buoy wind speeds and 

Inspired by inter-calibration of scatterometers in Elyouncha and Neyt (2013), where sensors are inter-calibrated using CMOD5.N in forward mode using wind speeds and directions from global circulation models, we calculate sensor-specific corrections of NRCS. These corrections are applied to the NRCS observed by different SAR sensors in order to achieve an inter-calibrated SAR data series.

The starting point for the inter-calibration is the set of SAR wind fields obtained within the domain shown in Figure 1 with a distance of at least $20 \mathrm{~km}$ from the shore. In addition to the 10-m wind speed, each data file contains the observed NRCS, radar incidence angle, and look direction as well as wind speeds and directions from a global circulation model (cf. Section 2.1). Since model wind speeds and directions are available for all SAR acquisition times and all locations, it is convenient to use these for the inter-calibration analysis to achieve the largest possible number of data points for the correction of NRCS. All the listed data layers are resampled to $10 \mathrm{~km}$ grid cells to make the SAR observations more comparable to the resolution of the model data and to reduce our computational effort. Resolution cells with wind speeds from either model or SAR-derived winds below $2 \mathrm{~m} \mathrm{~s}^{-1}$ and above $20 \mathrm{~m} \mathrm{~s}^{-1}$ are filtered out.

NRCS is retrieved from the model wind speed and direction and the radar viewing geometry in a similar fashion as in Section 3.4. Residuals with respect to the observed NRCS (in dB space) are then calculated within incidence angle bins of $1^{\circ}$ and a linear fit is made based on the median values. We split our data set according to sensor, polarization, and scan modes. Additionally, we take into account that the calibration of a sensor can change over time by calculating NRCS-corrections on a monthly basis. For each month, data from the previous full 

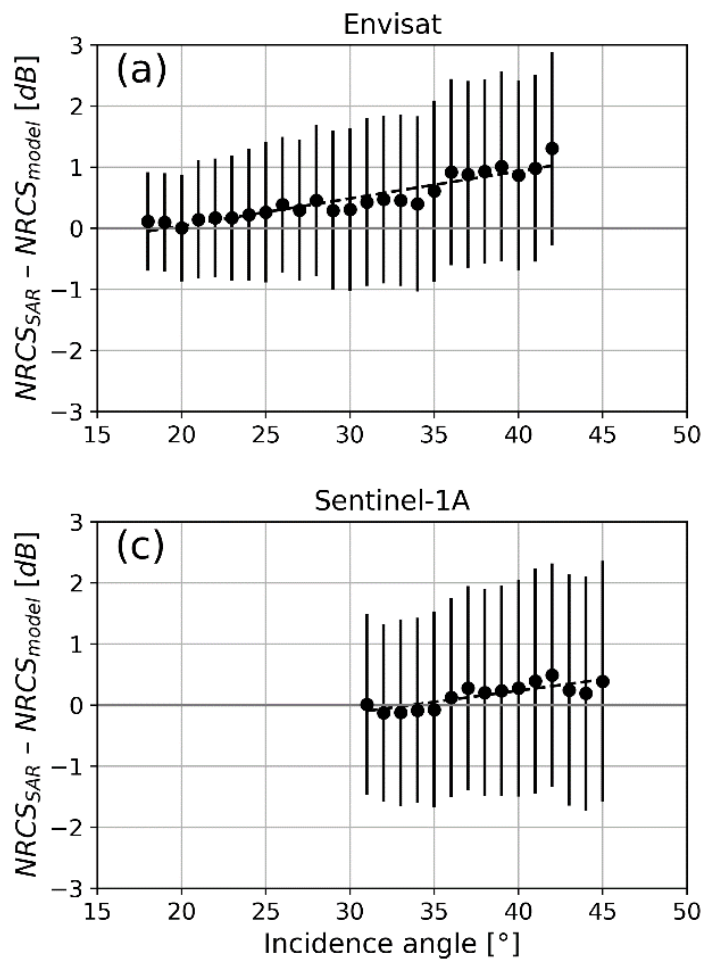
same 12 months are used for correction. for Sentinel-1A/B. year is used. For the first 12 months a given sensor is in operation, model data covering the

Figure 5 shows examples of the fitted linear functions for one year of data from Envisat, Sentinel-1A commissioning phase, Sentinel-1A, and Sentinel-1B. A clear offset is seen for Envisat, which increases with the incidence angle. The NRCS residuals are less pronounced
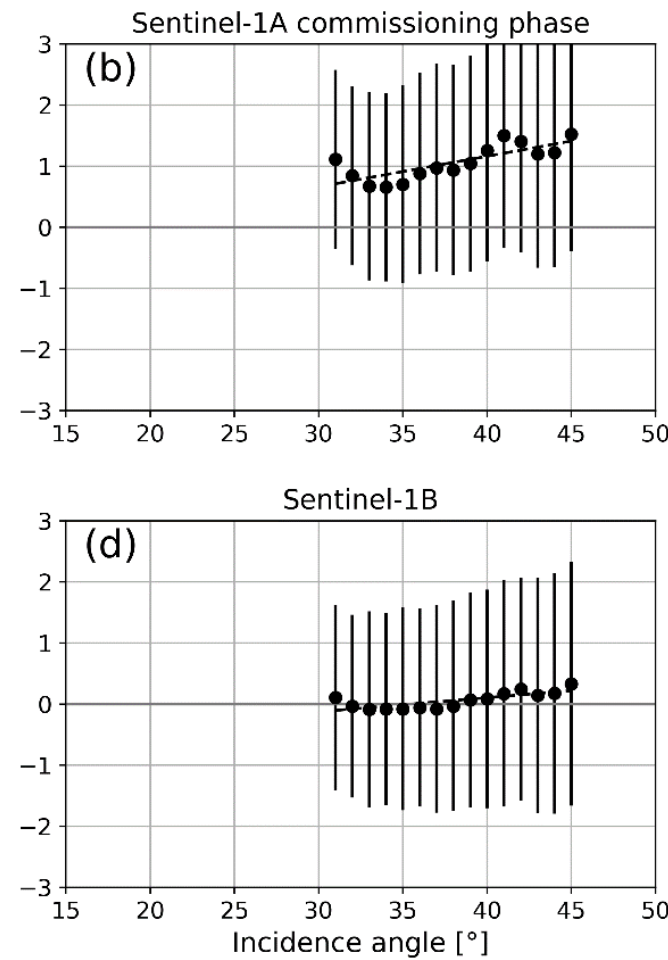

360

Figure 5. Examples showing linear fits to the NRCS residual per incidence angle based on one year of data from (a) Envisat (2008-03 to 2009-03); (b) Sentinel-1A commissioning phase (2014-11 to 2015-11); (c) Sentinel-1A (2017-04 to 2018-04); and (d) Sentinel-1B (2017-04 to
2018-04). 
Subtracting the linear fits from the NRCS observations made by Envisat and Sentinel-1 corrects the bias and the slope of NRCS in $\mathrm{dB}$ space:

$$
\sigma_{I C}^{0}(\theta)=\sigma^{0}(\theta)-f i t(y e a r, \theta)
$$

369 where $\sigma^{0}[\mathrm{~dB}]$ is the NRCS and $\theta\left[^{\circ}\right]$ is the radar incidence angle. The subscript ' $I C^{\text {' }}$ denotes 370 that NRCS is now inter-calibrated between the sensors. Figure 6 illustrates the entire processing chain of the inter-calibration method applied here.

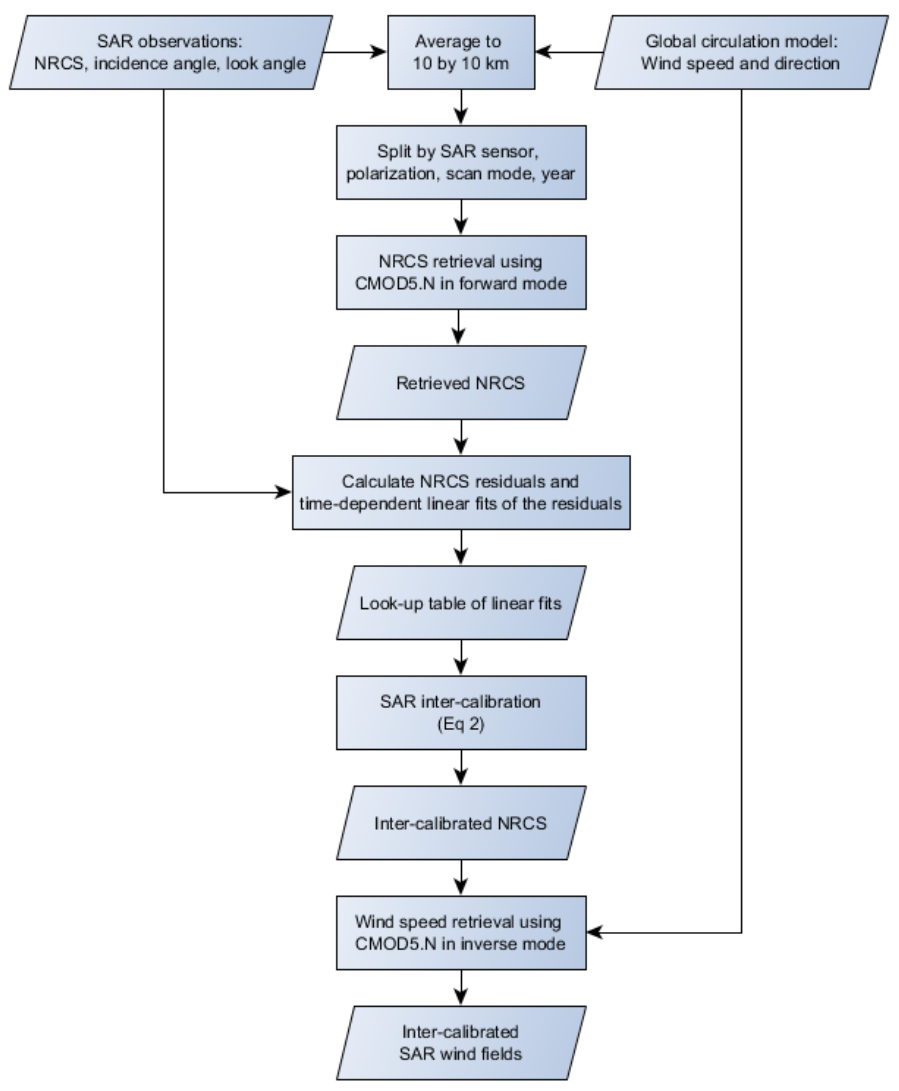
wind speeds and directions. We can therefore return to the ocean buoy observations of wind 

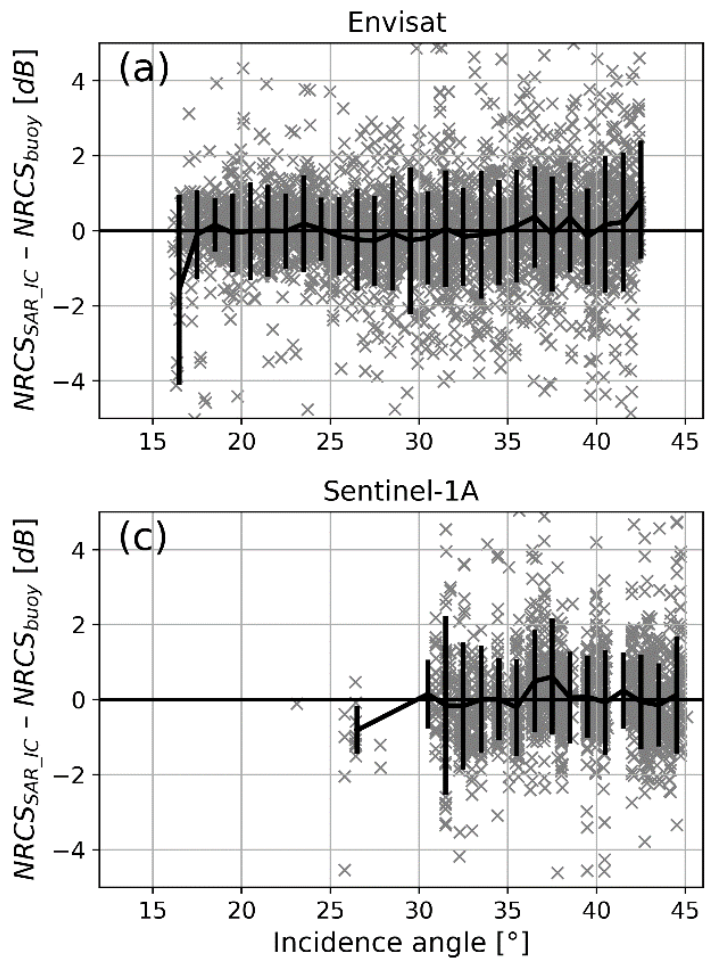

speed and use these as an independent reference data set. In the following, we compare the inter-calibrated NRCS and SAR wind speed retrievals to the buoy observations.

Figure 7 shows residuals between measured and retrieved NRCS as a function of the radar incidence angle. The plots are comparable to those in Figure 4; the only difference being that the NRCS measured from SAR is now inter-calibrated. As a result, residuals of NRCS are very close to zero for the entire span of incidence angles. It is remarkable how the large residuals that we found initially for Sentinel-1 during the commissioning phase are now reduced to a level similar to that of the later Sentinel-1 data series.
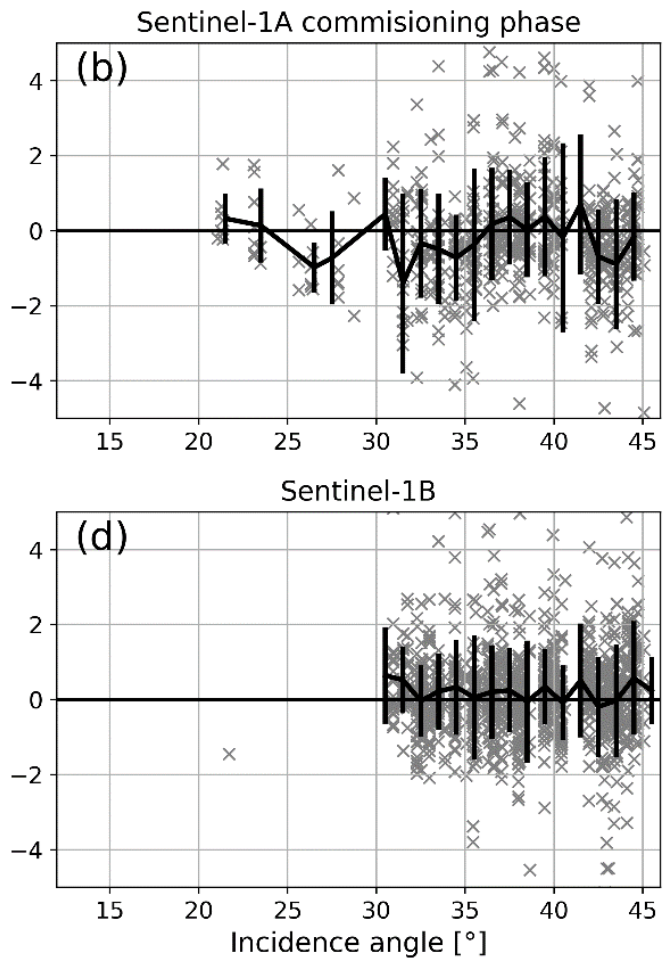

Figure 7. Residuals between measured and retrieved NRCS after inter-calibration of NRCS for (a) Envisat; (b) Sentinel-1A commissioning phase; (c) Sentinel-1A; and (d) Sentinel-1B. 
$392 \quad 5.1$ Wind speed retrieval from corrected NRCS

393 Once we have inter-calibrated the NRCS, we apply CMOD5.n in inverse mode to retrieve 394 wind speeds once again. Wind speed residuals with respect to the buoy observations are 395 shown as a function of the radar incidence angle in Figure 8. The plots are comparable to 396 plots in Figure 3 made before the SAR inter-calibration. The inter-calibrated SAR

397 observations lead to much smaller wind speed residuals, especially for Envisat, and there is no 398 longer a systematic increase of residuals for increasing incidence angles.

399

400 It is evident from Figure 7 and Figure 8 that our linear correction of the NRCS works best for 401 radar incidence angles above $25^{\circ}$. At very low incidence angles, few or no Sentinel-1 A/B 402 samples are available for fitting a linear function between the radar incidence angle and 403 NRCS residuals. The linear relations found for Envisat at very low incidence angles differ 404 from those found at higher incidence angles. To optimize the wind speed accuracy, we 405 recommend eliminating any data obtained with incidence angles lower than $25^{\circ}$. The 406 following results are calculated with this filter in place. 

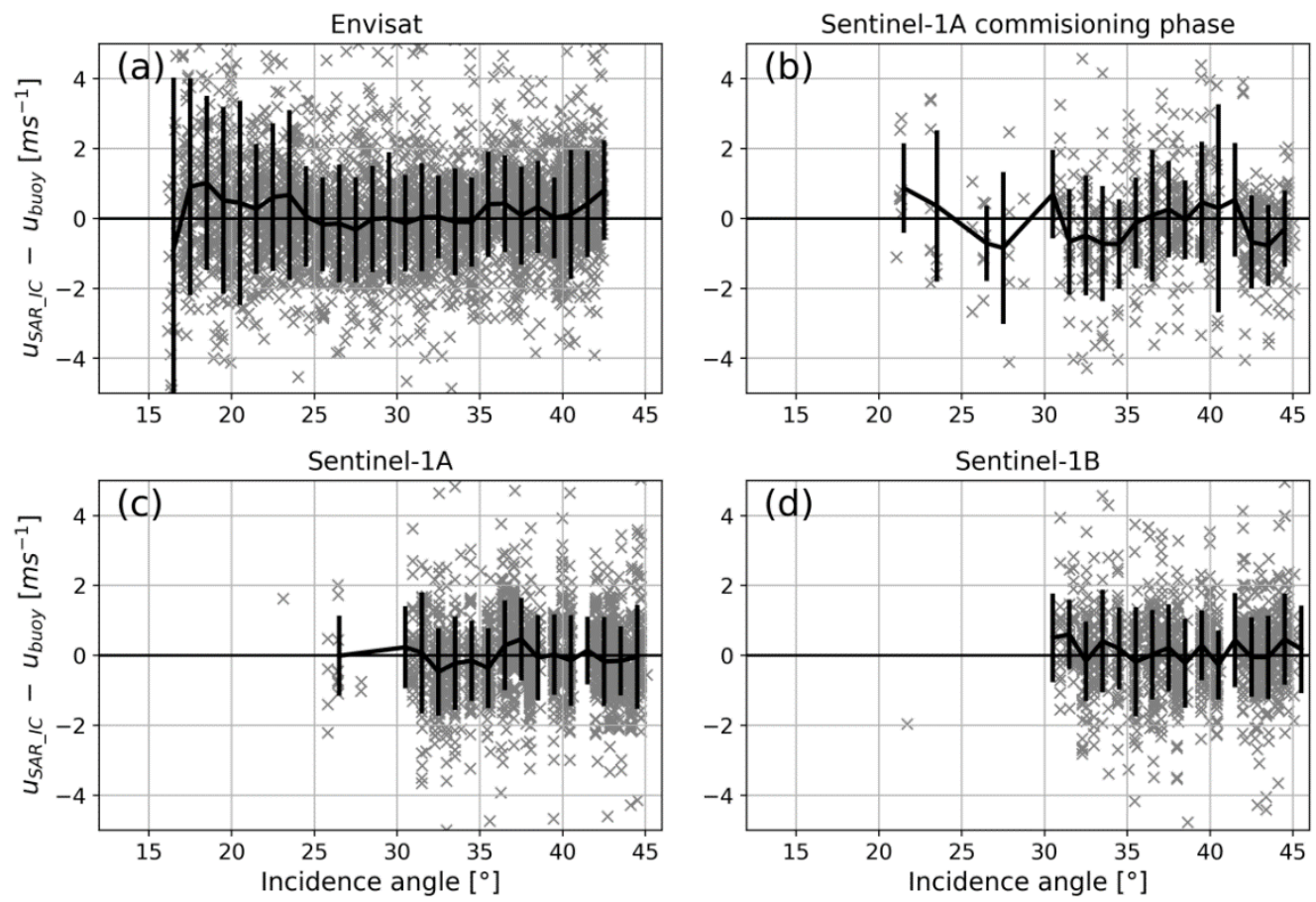

407

408

409

410

411

412

413

414

415

416

417

418

419

Figure 8. Residuals between SAR and buoy wind speeds as a function of radar incidence angle after SAR inter-calibration for (a) Envisat; (b) Sentinel-1A commissioning phase; (c)

Sentinel-1A; and (d) Sentinel-1B.

5.2 Effects of inter-calibration on the wind speed accuracy

In Table 2, we saw large differences in the accuracy of default wind speed retrievals from SAR observations acquired with VV and HH polarization. The majority of the HH-polarized SAR scenes in our data set were acquired by Envisat. Table 3 shows how the inter-calibration has removed any wind speed bias for retrievals based on Envisat observations with both VV and $\mathrm{HH}$ polarization. RMSE is also reduced for both VV and $\mathrm{HH}$ but its absolute value remains higher for scenes acquired with $\mathrm{HH}$ polarization. 
423 Figure 9 shows scatter plots of the buoy and SAR wind speeds per sensor after inter-

424

425

426

427

428

429

Table 3. Summary of comparisons between SAR and buoy wind speeds retrieved from Envisat observations with VV and HH polarization before and after inter-calibration.

\begin{tabular}{|l|c|c|c|c|}
\hline Polarization & \multicolumn{2}{|c|}{ VV } & \multicolumn{2}{c|}{ HH } \\
& Default & Inter- & Default & calibrated \\
& & calibrated & & 216 \\
\hline $\mathrm{N}$ & 1978 & 1978 & 216 & 0.07 \\
\hline Bias $\left[\mathrm{m} \mathrm{s}^{-1}\right]$ & 0.87 & 0.07 & 1.42 & 1.92 \\
\hline RMSE $\left[\mathrm{m} \mathrm{s}^{-1}\right]$ & 1.80 & 1.44 & 2.77 & \\
\hline
\end{tabular}

calibration of the NRCS. The number of samples given for each plot is a bit lower than in Figure 2, especially for Envisat. This is due to the filtering of low incidence angles, which was applied in connection with the inter-calibration. In contrast to the plots in Figure 2, we now see a consistency between plots for different SAR sensors. All four plots suggest that SAR winds overestimate buoy observations at low wind speeds up to 7-9 $\mathrm{m} \mathrm{s}^{-1}$ and underestimate with respect to the buoy observations for higher wind speeds. 

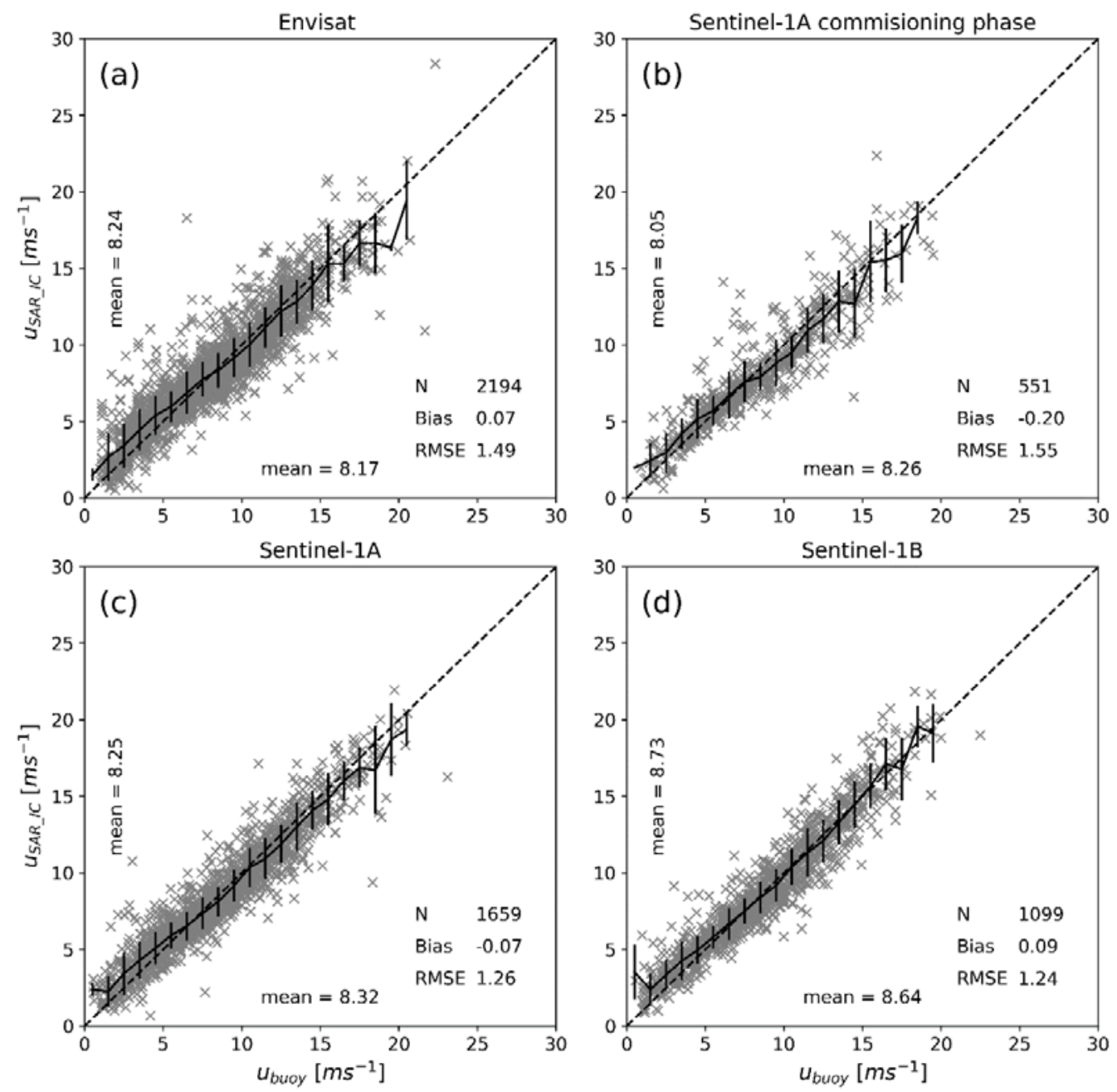

430

435 In Table 4, we present an overview of statistics per SAR sensor before and after the SAR

436 inter-calibration and using the same set of samples. The inter-calibration consistently leads to 437 a lower RMSE and biases that are close to zero for all sensors.

Figure 9. Comparisons of wind speeds retrieved from inter-calibrated SAR observations against buoy wind speeds for (a) Envisat; (b) Sentinel-1A commissioning phase; (c) Sentinel1A; and (d) Sentinel-1B. 

calibration.

\begin{tabular}{|c|c|c|c|c|c|c|c|c|}
\hline & \multicolumn{2}{|c|}{ Envisat } & \multicolumn{2}{|c|}{$\begin{array}{c}\text { Sentinel-1A } \\
\text { commissioning } \\
\text { phase }\end{array}$} & \multicolumn{2}{|c|}{ Sentinel-1A } & \multicolumn{2}{|c|}{ Sentinel-1B } \\
\hline $\begin{array}{l}\text { Processing } \\
\text { choice }\end{array}$ & Default & $\begin{array}{l}\text { Inter- } \\
\text { calibr } \\
\text { ated }\end{array}$ & Default & $\begin{array}{l}\text { Inter- } \\
\text { calibrat } \\
\text { ed }\end{array}$ & Default & $\begin{array}{l}\text { Inter- } \\
\text { calibrate } \\
\text { d }\end{array}$ & Default & $\begin{array}{l}\text { Inter- } \\
\text { calibrate } \\
\text { d }\end{array}$ \\
\hline $\mathrm{N}$ & 2194 & 2194 & 551 & 551 & 1659 & 1659 & 1099 & 1099 \\
\hline $\begin{array}{l}\text { Bias } \\
{\left[\mathrm{m} \mathrm{s}^{-1}\right]}\end{array}$ & 0.92 & 0.07 & 0.92 & -0.20 & 0.16 & -0.07 & 0.18 & 0.09 \\
\hline $\begin{array}{l}\text { RMSE } \\
{\left[\mathrm{m} \mathrm{s}^{-1}\right]}\end{array}$ & 1.92 & 1.49 & 1.93 & 1.55 & 1.30 & 1.26 & 1.26 & 1.24 \\
\hline
\end{tabular}

The effect of SAR inter-calibration on wind speed retrievals over time is illustrated in Figure

10. The plot shows how there is a drift of the SAR wind speed accuracy with respect to

reference measurements at the buoy stations during Envisat’s lifetime. Our correction of NRCS leads to a significant reduction of wind speed residuals during the entire Envisat eera.

446 For Sentinel-1A/B, we see large wind speed residuals for the first two years of operation,

447 which include the commissioning phase of the sensors. The SAR inter-calibration efficiently compensates for wind speed biases so the residuals for Sentinel-1A/B are less than $+/-0.2 \mathrm{~m} \mathrm{~s}$

$449{ }^{1}$ at any given time. From the beginning of 2016, the residuals between SAR and reference 450 wind speeds are small and the need for NRCS correction is less pronounced. 


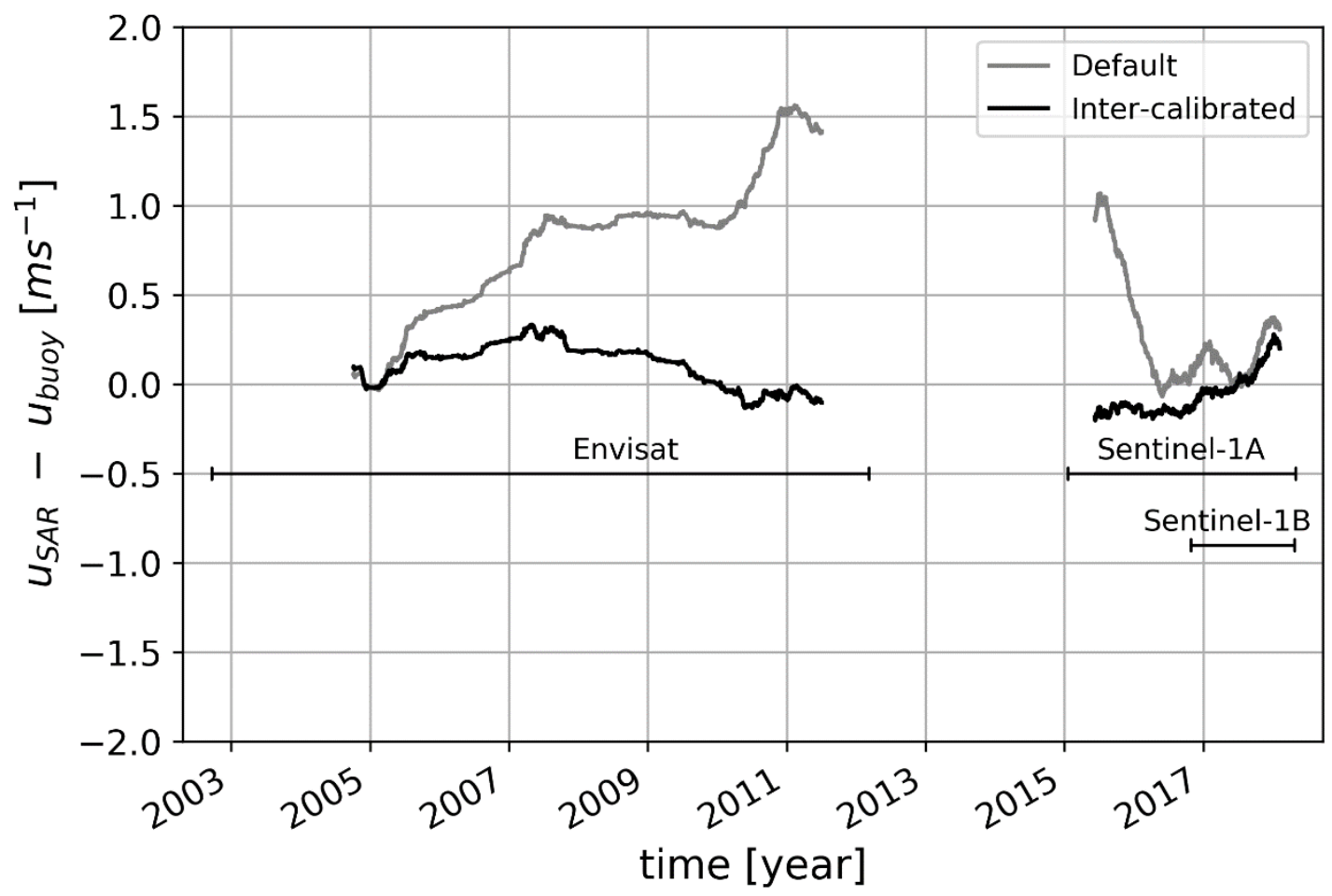

451

Figure 10. Residuals of the SAR mean wind speed with respect to buoy observations over

453

454

455

456

457

458

459

460

461

462

463

464

time. The grey curve is based on default SAR wind retrievals and the black curve is based on wind retrievals from inter-calibrated SAR observations.

Our results indicate that we have successfully removed biases on wind retrievals from the different SAR sensors. The bias removal is crucial for merging of the wind speeds retrieved from Envisat and Sentinel-1A/B to a single time series, which is desired for e.g. wind energy resource assessment. In the following, we will examine the effect of inter-calibration on the wind resource we can estimate for each of the buoy locations.

6. Wind resource assessment

The principle of satellite based wind resource mapping is similar to that of wind resource assessment from time series observations e.g. with a meteorological mast (Troen and 
Petersen, 1989) or from outputs of numerical models (Hahmann et al., 2015). For a given grid

466 cell, a time series of SAR wind samples can be constructed and analyzed statistically. A

467 Weibull function is fitted to the frequency distribution of wind speed bins. The function is

468 defined by a scale parameter, $A$ and a shape parameter, $k$. From these, the wind power density,

$469 E\left(\mathrm{~W} \mathrm{~m}^{-2}\right)$ is calculated:

470

471

$$
E=\frac{1}{2} \rho A^{3} \Gamma\left(1+\frac{3}{k}\right)
$$

472

473 where $\rho$ is the air density (here set to $1.23 \mathrm{~kg} \mathrm{~m}^{-3}$ ). Repeating this analysis for each point in a 474 geographical grid will lead to wind resource maps (Badger et al., 2010; Doubrawa et al., 475 2015; Hasager et al., 2015)

476

477 In order to examine the effect of SAR inter-calibration on wind resource estimates, we 478 calculate the wind power density for each buoy location. The wind power densities are listed 479 in together with the residuals between SAR and buoy wind resources before and after inter480 calibration of the SAR data sets. For ten of the 12 buoy locations, we find that the wind power 481 density estimated from SAR after inter-calibration shows a lower bias with respect to the 482 buoy observations. The average numerical deviation from the buoy observations is $20 \%$ 483 before and 8\% after SAR inter-calibration. 
Table 5. Wind power densities $\left(\mathrm{W} \mathrm{m}^{-2}\right)$ for the twelve investigated buoy locations.

\begin{tabular}{|c|c|c|c|c|c|c|}
\hline Station & $\mathrm{N}$ & $E_{\text {buoy }}$ & $\mathrm{E}_{\mathrm{SAR}}$ & ESAR_IC & $E_{\text {SAR }}-E_{\text {buoy }}$ & ESAR_IC $_{\text {S E Euoy }}$ \\
\hline BRITTANY & 735 & 559 & 632 & 545 & 73 & -14 \\
\hline 62091 & 644 & 506 & 582 & 486 & 76 & -20 \\
\hline GASCOIGNE & 557 & 450 & 466 & 399 & 16 & -51 \\
\hline K7 & 496 & 825 & 948 & 784 & 123 & -41 \\
\hline TWEms & 475 & 515 & 595 & 501 & 80 & -14 \\
\hline 62093 & 456 & 638 & 839 & 712 & 201 & 74 \\
\hline 62094 & 449 & 500 & 611 & 489 & 111 & -11 \\
\hline DtBucht & 441 & 461 & 565 & 442 & 104 & -19 \\
\hline NsbII & 383 & 681 & 598 & 523 & -83 & -158 \\
\hline 62092 & 276 & 514 & 719 & 563 & 205 & 49 \\
\hline K1 & 260 & 778 & 895 & 727 & 117 & -51 \\
\hline K5 & 222 & 819 & 1013 & 885 & 194 & 66 \\
\hline K2 & 109 & 770 & 994 & 872 & 224 & 102 \\
\hline
\end{tabular}

490

491

492 It is not clear why the inter-calibration leads to higher residuals at the two sites Gascoigne and

493 Nsbll. One explanation could be that the fitting of a Weibull function introduces some

494 uncertainty to the wind resource estimation. In fact, when we calculate a simple mean value of

495 the wind speed observations, the two stations show better agreement with the reference data

496 after inter-calibration. Other possible reasons for the deviation at the two stations could be

497 issues with the buoy data quality e.g. inaccurate positioning, instrument faults, or biases

498 caused by the vertical extrapolation of wind speed observations. 

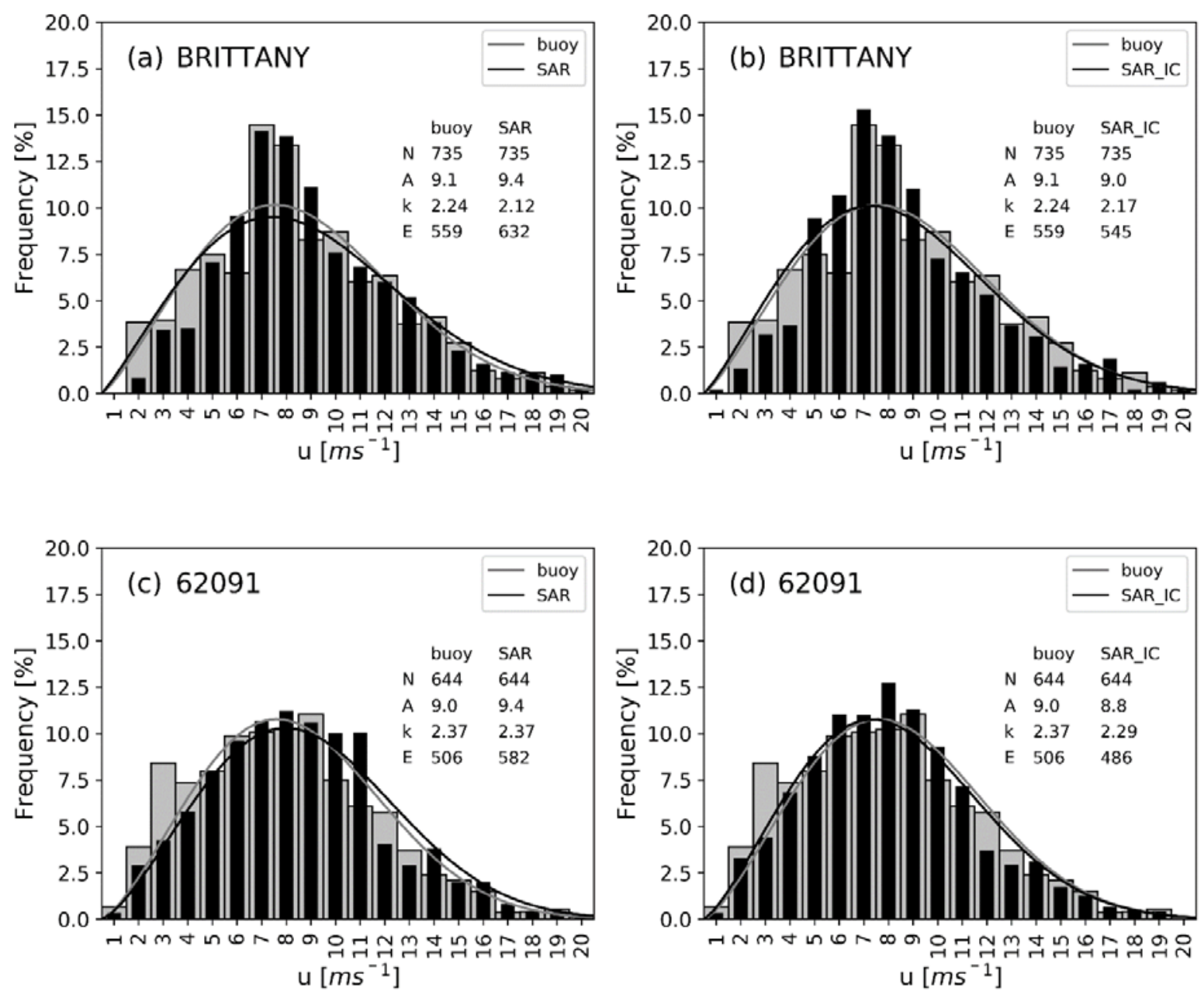

502

503

504

505

506

507

508

509

510

Figure 11. Weibull distributions for the two sites Brittany (a-b) and 62091 (c-d). The Weibull distributions are shown before and after SAR inter-calibration.

Figure 11 shows examples of the Weibull distribution for one site exposed to open sea conditions (Brittany) and another site in the enclosed Irish Sea (62091). The two sites have the highest number of SAR samples of the sites investigated. The prevailing wind direction for Brittany is from the south-west. The Weibull fit based on inter-calibrated SAR observations fits almost perfectly with that of the buoy observations. This is reflected in the Weibull-k parameter, which changes from 2.12 to 2.17 after inter-calibration. The Weibull- $A$ 
parameter is also much closer to the buoy observations after inter-calibration and the absolute residual of the wind power density improves from 73 to $14 \mathrm{~W} \mathrm{~m}^{-2}$.

At the buoy station 62091, prevailing winds are from more southerly directions due to channeling effects within the Irish Sea. The difference between Weibull curves before and after inter-calibration of the SAR data is less pronounced than for Brittany. In fact, the values of Weibull $k$ are identical to the buoy observations before inter-calibration whereas a difference of 0.08 is found after inter-calibration. As for Brittany, we find that Weibull $A$ and the wind power density is reduced significantly after the SAR inter-calibration.

Table 6. Summary of the bias, RMSE, and MAE of wind resource assessments averaged for the 12 buoy stations investigated. The mean wind speed (U), wind power density (E), Weibull scale (A), and shape ( $k$ ) parameters are calculated before and after the inter-calibration of SAR observations.

\begin{tabular}{|c|c|c|c|c|c|c|c|}
\hline \multicolumn{2}{|c|}{$U\left[\mathrm{~m} \mathrm{~s}^{-1}\right]$} & \multicolumn{2}{|c|}{$E\left[\mathrm{~W} \mathrm{~m}{ }^{-2}\right]$} & \multicolumn{2}{|c|}{$A\left[\mathrm{~m} \mathrm{~s}^{-1}\right]$} & \multicolumn{2}{|c|}{$k[-]$} \\
\hline Default & $\begin{array}{c}\text { Inter- } \\
\text { calibrated }\end{array}$ & Default & $\begin{array}{c}\text { Inter- } \\
\text { calibrated }\end{array}$ & Default & $\begin{array}{c}\text { Inter- } \\
\text { calibrated }\end{array}$ & Default & $\begin{array}{c}\text { Inter- } \\
\text { calibrated }\end{array}$ \\
\hline
\end{tabular}

\begin{tabular}{ll|ll|ll|ll|l}
\hline Bias & 0.60 & 0.05 & 111 & -7 & 0.49 & -0.10 & -0.05 & -0.06 \\
RMSE & 0.67 & 0.27 & 138 & 65 & 0.57 & 0.28 & 0.16 & 0.12 \\
MAE & 0.61 & 0.21 & 124 & 52 & 0.50 & 0.26 & 0.13 & 0.11
\end{tabular}

The bias, RMSE, and Mean Absolute Error (MAE) averaged for all 12 buoy stations are summarized in Table 6 . The bias on $U$ is reduced to almost zero and this reduces the bias on both $E$ and Weibull-A significantly. All three biases change from positive to negative values 
after the SAR inter-calibration and this leads to more conservative estimates of the wind resource. The bias on Weibull- $k$ remains the same. The RMSE is also reduced for $U, E$, and Weibull- $A$ indicating a lower uncertainty of wind resource estimates after the SAR intercalibration.

\section{Discussion}

Our initial processing of wind speed maps from Envisat and Sentinel-1A/B observations lead to a positive bias for all the SAR sensors investigated but with a large offset between Envisat and Sentinel-1A/B. This is critical if a long time series based on all available SAR observations is desired e.g. for wind resource assessment. The RMSE found in our initial comparisons with buoy observations of wind speed are similar to values found in previous studies based on Envisat (Chang et al., 2015; Doubrawa et al., 2015; Hasager et al., 2015a; 2015b; 2011; Takeyama et al., 2013a; 2013b) and Sentinel-1A/B (Ahsbahs et al., 2018; Lu et al., 2018; Monaldo et al., 2016). Our analyses confirm that observations from the two Sentinel-1 sensors A and B lead to wind speeds having almost the same level of accuracy with respect to reference data sets if the commissioning phase of the Sentinel-1A data series is neglected.

Our analyses show for the first time how observations from different SAR sensors can be inter-calibrated in the same fashion as scatterometer observations are inter-calibrated in connection with CDR development (cf. Section 1). So far, efforts to inter-calibrate SAR observations from different sensors have been limited since relatively few users of the observations see a need for long-term climatological variables. Efforts have instead been dedicated to determining the most suitable GMF for SAR wind retrieval in different areas of the world (Christiansen et al., 2006; Hasager et al., 2015; Takeyama et al., 2013b). Our results 
indicate that a single GMF cannot retrieve wind speeds from multiple sensors accurately as long as NRCS residuals vary according to sensor type, scan mode, incidence angle, and over the sensor lifetime. It is thus necessary to inter-calibrate the NRCS before wind retrieval processing unless a new GMF is developed specifically for the SAR sensors in question so that inter-calibration is indirectly performed through tuning of the GMF (Lu et al., 2018).

The inter-calibration method presented here leads to a significant reduction of the offset between wind speed retrievals from Envisat and Sentinel-1A/B observations. After intercalibration, the average wind speed bias does not exceed $+/-0.20 \mathrm{~m} \mathrm{~s}^{-1}$ for any sensor investigated here and the RMSE on wind speeds is less than $1.55 \mathrm{~m} \mathrm{~s}^{-1}$ with respect to ocean buoy observations. For Sentinel-1A/B, we achieve almost zero wind speed bias and a RMSE as low as $1.24 \mathrm{~m} \mathrm{~s}^{-1}$. The difference between wind resource estimates from SAR and the buoy wind speeds is reduced as a result of inter-calibration for ten of the 12 sites investigated. The inter-calibration removes positive biases from the SAR observations and this leads to lower and more conservative estimates of the wind power density. From an industry perspective, it is important to operate with conservative rather than over-optimistic resource estimates to ensure that potential new wind farms can deliver on feasibility as expected.

This work relies on several assumptions, which may be investigated further in future research. Wind speed retrievals using CMOD5.n result in the ENW, which is offset from the real wind speed (Kara et al., 2008; Portabella and Stoffelen, 2009). Over the seas of Northern Europe, this offset is found to be smaller than $0.1 \mathrm{~m} \mathrm{~s}^{-1}$ for the height $10 \mathrm{~m}$ and it increases for higher levels in the atmosphere (Badger et al., 2016). Our comparisons between SAR and model wind speeds and the calculation of NRCS corrections do not take the offset between ENW and real winds into account. We assume the offset to be constant over time from the Envisat 
to the Sentinel-1A/B era and so, the impact will be constant for all the SAR data sets investigated. In reality, the atmospheric stability has a seasonal variation as it is temperaturedriven. A seasonal inter-calibration analysis would be helpful for quantifying the effect of atmospheric stability.

In connection with the fitting of linear functions to calculate NRCS corrections, we also assume that the modelled wind speeds will on average converge to the true mean wind speed (both spatially and temporally); otherwise we are adjusting to an offset wind speed.

Comparisons between model and in situ wind speeds (not shown here) indicate that the model simulations are indeed consistent with the real wind speeds in the long-term. Our linear fitting is performed for the wind speed interval $2-20 \mathrm{~m} \mathrm{~s}^{-1}$. A high uncertainty is anticipated for extremely low and high wind speeds due to lower sampling rates and a saturation problem of GMFs at high wind speeds. Work is ongoing in the satellite wind community to resolve extremely high wind speeds thanks to the availability of new cross-polarized SAR sensors (Mouche et al., 2017; Zadelhoff et al., 2014). Further developments of our inter-calibration method might take high wind speeds better into account.

The spatial and temporal collocation of data sets in our analyses add uncertainties to our findings because: $i$ ) model simulations and buoy observations are available every hour and the offset in time from the SAR observations may thus be up to 30 minutes; ii) the exact geolocation of ocean buoys can be difficult to determine from the metadata provided with the wind speed data; and iii) the measurement height for the buoy winds may not be accurate and interpolation to the height of $10 \mathrm{~m}$ adds additional uncertainty to wind speed estimates. In order to examine the robustness of our inter-calibration method, it would be valuable to test it for other independent sites where high-quality wind observations are available. The ideal test 
608

609

610

site would provide offshore wind measurements at the height $10 \mathrm{~m}$ together with air-sea temperature differences suitable for atmospheric stability correction.

The successful inter-calibration of SAR data from the European Space Agency presented here could potentially be extended to cover other SAR sensors and scan modes. As an example, long C-band SAR data series have been acquired by Radarsat-1/2, which is soon to be continued with the Radarsat Constellation Mission. Sensors operating at X-band or L-band represent other possible extensions of the data series investigated here. An added benefit of using SAR observations from a variety of sensors in combination would be that diurnal wind speed variability can be better resolved.

At present, the calibration of individual SAR sensors is the responsibility of different space agencies and it is typically governed by different requirements. The method for intercalibration described here can be applied by any end user of SAR data and it is thus promising for inter-calibration of multiple SAR data sets obtained in the past, present and future.

Potentially, an inter-calibrated long-term record of SAR wind speeds could be established and offered through publicly available data portals. This would facilitate the best possible accuracy on long-term average wind speeds offshore for many applications including wind energy resource assessment.

\section{Conclusion}

We have presented a method for inter-calibration of SAR observations with the purpose of constructing a long-term record of wind speed retrievals from SAR. Correction of the NRCS prior to wind retrieval processing efficiently removes biases on wind speeds from Envisat and Sentinel-1A/B observations. The correction varies according to the SAR sensor, scan mode, 
radar incidence angle, and also over the sensor lifetime. The inter-calibration leads to a significant reduction of wind speed biases and uncertainties expressed through the RMSE.

Wind resource estimates become more conservative as a result of the SAR inter-calibration.

Our successful calculation of a long-term wind speed record form SAR observations is promising and has a potential for extension using other SAR sensors from the past, present and future. Ultimately, this could lead to establishment of a new derived product offering long-term SAR wind data for wind energy resource assessment and other applications.

\section{Acknowledgements}

This work received funding from the EU H2020 program under grant agreement no. 730030 (CEASELESS project).

\section{References}

Ahsbahs, T., Badger, M., Karagali, I., Larsén, X.G., 2017. Validation of Sentinel-1A SAR coastal wind speeds against scanning LiDAR. Remote Sens. 9. https://doi.org/10.3390/rs9060552

Ahsbahs, T., Badger, M., Volker, P., Hansen, K.S., Hasager, C.B., 2018. Applications of satellite winds for the offshore wind farm site Anholt. Wind Energy Sci. 3, 573-588. https://doi.org/10.5194/wes-2018-2

Badger, M., Badger, J., Nielsen, M., Hasager, C.B., Peña, A., 2010. Wind Class Sampling of Satellite SAR Imagery for Offshore Wind Resource Mapping. J. Appl. Meteorol. Climatol. https://doi.org/10.1175/2010JAMC2523.1

Badger, M., Peña, A., Hahmann, A.N., Mouche, A.A., Hasager, C.B., 2016. Extrapolating satellite winds to turbine operating heights. J. Appl. Meteorol. Climatol. 55. https://doi.org/10.1175/JAMC-D-15-0197.1 
656

657

658

659

660

661

662

663

664

665

666

667

668

669

670

671

672

673

674

675

676

677

678

679

680

Chang, R., Zhu, R., Badger, M., Hasager, C., Xing, X., Jiang, Y., 2015. Offshore Wind Resources Assessment from Multiple Satellite Data and WRF Modeling over South China Sea. Remote Sens. 7, 467-487. https://doi.org/10.3390/rs70100467

Christiansen, M.B., Koch, W., Horstmann, J., Hasager, C.B., Nielsen, M., 2006. Wind resource assessment from C-band SAR. Remote Sens. Environ. 105, 68-81.

Christy, J.R., Spencer, R.W., Lobl, E.S., 1998. Analysis of the merging procedure for the MSU daily temperature time series. J. Clim. 11, 2016-2041. https://doi.org/10.1175/1520-0442-11.8.2016

Dagestad, K.-F., Horstmann, J., Mouche, A., Perrie, W., Shen, H., Zhang, B., Li, X., Monaldo, F., Pichel, W., Lehner, S., Badger, M., Hasager, C.B., Furevik, B., Foster, R.C., Falchetti, S., Caruso, M., Vachon, P., 2012. Wind retrieval from synthetic aperture radar - an overview, in: Proceedings of SEASAR 2012 Advances in SAR Oceanography, Tromsø Norway.

Doubrawa, P., Barthelmie, R.J., Pryor, S.C., Hasager, C.B., Badger, M., Karagali, I., 2015. Satellite winds as a tool for offshore wind resource assessment: The Great Lakes Wind Atlas. Remote Sens. Environ. 168. https://doi.org/10.1016/j.rse.2015.07.008

Elyouncha, A., Neyt, X., 2013. C-band satellite scatterometer intercalibration. IEEE Trans. Geosci. Remote Sens. 51, 1478-1491. https://doi.org/10.1109/TGRS.2012.2217381

Hahmann, A.N., Vincent, C.L., Peña, A., Lange, J., Hasager, C.B., 2015. Wind climate estimation using WRF model output: Method and model sensitivities over the sea. Int. J. Climatol. 35, 3422-3439. https://doi.org/10.1002/joc.4217

Hasager, C.B., Badger, M., Nawri, N., Furevik, B.R., Petersen, G.N., Bjornsson, H., Clausen, N.-E., 2015a. Mapping Offshore Winds Around Iceland Using Satellite Synthetic Aperture Radar and Mesoscale Model Simulations. IEEE J. Sel. Top. Appl. Earth Obs. Remote Sens. 8. https://doi.org/10.1109/JSTARS.2015.2443981 
Hasager, C.B., Badger, M., Peña, A., Larsén, X.G., Bingöl, F., 2011. SAR-based wind resource statistics in the Baltic Sea. Remote Sens. 3. https://doi.org/10.3390/rs3010117

Hasager, C.B., Dellwik, E., Nielsen, M., Furevik, B., 2002. Validation of ERS-2 SAR offshore wind-speed maps in the North Sea. Int. J. Remote Sens.

Hasager, C.B., Mouche, A., Badger, M., Bingöl, F., Karagali, I., Driesenaar, T., Stoffelen, A., Peña, A., Longépé, N., 2015b. Offshore wind climatology based on synergetic use of Envisat ASAR, ASCAT and QuikSCAT. Remote Sens. Environ. 156. https://doi.org/10.1016/j.rse.2014.09.030

Hasager, C.B., Mouche, A., Badger, M., Bingöl, F., Karagali, I., Driesenaar, T., Stoffelen, A., Peña, A., Longépé, N., 2015. Offshore wind climatology based on synergetic use of Envisat ASAR, ASCAT and QuikSCAT. Remote Sens. Environ. 156, 247-263. https://doi.org/10.1016/j.rse.2014.09.030

Hersbach, H., 2010. Comparison of C-Band Scatterometer CMOD5.N Equivalent Neutral Winds with ECMWF. J. Atmos. Ocean. Technol. 27, 721-736. https://doi.org/10.1175/2009JTECHO698.1

Hersbach, H., Stoffelen, A., de Haan, S., 2007. An improved C-band scatterometer ocean geophysical model function: CMOD5. J. Geophys. Res. 112, 16 pp.

Kara, A.B., Wallcraft, A.J., Bourassa, M.A., 2008. Air-sea stability effects on the $10 \mathrm{~m}$ winds over the global ocean: Evaluations of air-sea flux algorithms. J. Geophys. Res. Ocean. 113, 1-14. https://doi.org/10.1029/2007JC004324

Karagali, I., Larsén, X., Badger, M., Peña, A., Hasager, C., 2013. Spectral Properties of ENVISAT ASAR and QuikSCAT Surface Winds in the North Sea. Remote Sens. 5, 6096-6115. https://doi.org/10.3390/rs5116096

Khvorostovsky, K.S., 2012. Merging and analysis of elevation time series over greenland ice sheet from satellite radar altimetry. IEEE Trans. Geosci. Remote Sens. 50, 23-36. 
https://doi.org/10.1109/TGRS.2011.2160071

707

708

709

710

711

712

713

714

715

716

717

718

719

720

721

722

723

724

725

726

727

728

729

730

Liu, G., Yang, X., Li, X., Zhang, B., Pichel, W., Li, Z., Zhou, X., 2013. A Systematic Comparison of the Effect of Polarization Ratio Models on Sea Surface Wind Retrieval From C-Band Synthetic Aperture Radar. IEEE J. Sel. Top. Appl. Earth Obs. Remote Sens. 6, 1100-1108. https://doi.org/10.1109/JSTARS.2013.2242848

Lu, Y., Zhang, B., Perrie, W., Mouche, A.A., Li, X., Wang, H., 2018. A C-Band geophysical model function for determining coastal wind speed using synthetic aperture radar. IEEE J. Sel. Top. Appl. Earth Obs. Remote Sens. 11, 2417-2428. https://doi.org/10.1109/JSTARS.2018.2836661

Miranda, N., 2015. S-1A TOPS Radiometric Calibration Refinement \# 1.

Monaldo, F., Jackson, C., Li, X., Pichel, W.G., 2016. Preliminary Evaluation of Sentinel-1A Wind Speed Retrievals. IEEE J. Sel. Top. Appl. Earth Obs. Remote Sens. 9, 2638-2642. https://doi.org/10.1109/JSTARS.2015.2504324

Monaldo, F.M., Li, X., Pichel, W.G., Jackson, C.R., 2014. Ocean Wind Speed Climatology from Spaceborne SAR Imagery. Bull. Am. Meteorol. Soc. 95, 565-569. https://doi.org/10.1175/BAMS-D-12-00165.1

Mouche, A.A., Chapron, B., Zhang, B., Husson, R., 2017. Combined Co- and Cross-Polarized SAR Measurements Under Extreme Wind Conditions. IEEE Trans. Geosci. Remote Sens. 55, 6746-6755. https://doi.org/10.1109/TGRS.2017.2732508

Mouche, A.A., Hauser, D., Daloze, J.F., Guerin, C., 2005. Dual-polarization measurements at C-band over the ocean: Results from airborne radar observations and comparison with ENVISAT ASAR data. IEEE Trans. Geosci. Remote Sens. 43, 753-769.

National Research Council, 2004. Climate Data Records from Environmental Satellites: Interim Report. The National Academies Press, Washington DC. https://doi.org/10.17226/10944 
Portabella, M., Stoffelen, a., 2009. On Scatterometer Ocean Stress. J. Atmos. Ocean. Technol. 26, 368-382. https://doi.org/10.1175/2008JTECHO578.1

Quilfen, Y., Chapron, B., Elfouhaily, T., Katsaros, K., Tournadre, J., 1998. Observation of tropical cyclones by high-resolution scatterometry. J. Geophys. Res. 103, 7767-7786.

Schwerdt, M., Schmidt, K., Ramon, N.T., Klenk, P., Yague-Martinez, N., Prats-Iraola, P., Zink, M., Geudtner, D., 2017. Independent system calibration of sentinel-1B. Remote Sens. 9, 1-34. https://doi.org/10.3390/rs9060511

Stoffelen, A., Anderson, D.L.T., 1997. Scatterometer data interpretation: Estimation and validation of the transfer function CMOD4. J. Geophys. Res. 102, 5767-5780.

Stoffelen, A., Verspeek, J.A., Vogelzang, J., Verhoef, A., 2017. The CMOD7 Geophysical Model Function for ASCAT and ERS Wind Retrievals. IEEE J. Sel. Top. Appl. Earth Obs. Remote Sens. 10, 2123-2134. https://doi.org/10.1109/JSTARS.2017.2681806

Takeyama, Y., Ohsawa, T., Kozai, K., Hasager, C.B., Badger, M., 2013. Comparison of geophysical model functions for SAR wind speed retrieval in japanese coastal waters. Remote Sens. 5. https://doi.org/10.3390/rs5041956

Takeyama, Y., Ohsawa, T., Kozai, K., Hasager, C.B., Badger, M., 2013. Effectiveness of WRF wind direction for retrieving coastal sea surface wind from synthetic aperture radar. Wind Energy 16, 865-878.

Takeyama, Y., Ohsawa, T., Kozai, K., Hasager, C.B., Badger, M., 2010. Effect of Wind Direction on ENVISAT ASAR Wind Speed Retrieval, in: Proceedings (CD-ROM). Techno-Ocean Network, p. 8.

Thompson, D., Elfouhaily, T., Chapron, B., 1998. Polarization ratio for microwave backscattering from the ocean surface at low to moderate incidence angles. pp. 16711676.

Troen, I., Petersen, E.L., 1989. European Wind Atlas. Risø National Laboratory, Roskilde, 
Denmark.

757

758

759

760

761

762

763

764

765

766

Zadelhoff, G.J. Van, Stoffelen, A., Vachon, P.W., Wolfe, J., Horstmann, J., Belmonte Rivas, M., 2014. Retrieving hurricane wind speeds using cross-polarization C-band measurements. Atmos. Meas. Tech. 7, 437-449. https://doi.org/10.5194/amt-7-437-2014

Zeng, Y., Su, Z., Calvet, J.C., Manninen, T., Swinnen, E., Schulz, J., Roebeling, R., Poli, P., Tan, D., Riihelä, A., Tanis, C.M., Arslan, A.N., Obregon, A., Kaiser-Weiss, A., John, V.O., Timmermans, W., Timmermans, J., Kaspar, F., Gregow, H., Barbu, A.L., Fairbairn, D., Gelati, E., Meurey, C., 2015. Analysis of current validation practices in Europe for space-based climate data records of essential climate variables. Int. J. Appl. Earth Obs. Geoinf. 42, 150-161. https://doi.org/10.1016/j.jag.2015.06.006 